\title{
Dynamic Landscape Modelling: The Quest for a Unifying Theory
}

\author{
Cédric Gaucherel ${ }^{1}$, François Houllier ${ }^{2}$, Daniel Auclair ${ }^{2}$, and Thomas Houet $^{3}$ \\ ${ }^{1}$ French Institute of Pondicherry (UMIFRE 21 CNRS-MAEE), 11, St. Louis Street, Pondicherry, 605001, India, \\ Associated to INRA, AMAP laboratory, Montpellier, France, cedric.gaucherel@ifpindia.org \\ ${ }^{2}$ INRA, UMR AMAP, 34398, Montpellier, France \\ ${ }^{3}$ Laboratory of Geography of the Environment (GEODE), CNRS, University of Toulouse, 5 allées Antonio \\ Machado, 31058 Toulouse Cedex, France
}

Accepted: 24 February 2014

Published: 15 May 2014

\begin{abstract}
In the past 30 years, the notion of landscape has emerged in ecology as a result of both theoretical considerations and practical aspects of land use and land cover. This has generated a variety of numerical models addressing both methodological and thematic objectives. Scientists model landscapes for at least two reasons: to better understand the landscape dynamics themselves (called intrinsic needs) and to offer a realistic frame to support other ecological processes (extrinsic needs). This paper mainly concerns the intrinsic needs; it reviews and discusses the way the socioeconomic and/or ecological mechanisms of various landscapes have been explored through modelling approaches in the past. Our objective is to identify the possible lack of understanding in landscape dynamics and to propose a unified view of this complex object. We outline the links between the concepts of landscape and of models using a double-entry matrix, focusing on one hand on the four main terrestrial landscapes (agricultural, forested, arid and urban) and on the other hand on the main landscape model characteristics (explicit or neutral, patchy or continuous, and multi- or mono-scale).

The patterns and processes of each of the four landscape types, in particular, are analysed within a coherent framework. The heterogeneity of this yet coherent analytical matrix implies the need for unifying concepts and formalisms. The complexity theory and related concepts such as self-organization or formal grammar applied to landscape mosaics could help to further develop the mathematical formalisms necessary to assemble the various inner landscape processes. The discipline can now offer a theoretical dimension to dynamic landscape modelling aiming at understanding the mechanism unity underlying this complex object.
\end{abstract}

Keywords: Numerical simulations, Natural forcing, Human practices, Scaling law, Heterogeneity

This review is licensed under a Creative Commons Attribution-Non-Commercial 3.0 Germany License. http://creativecommons .org/licenses/by-nc/3.0/de/ 


\section{Imprint / Terms of Use}

Living Reviews in Landscape Research is a peer reviewed open access journal published by the Leibniz Centre for Agricultural Landscape Research (ZALF), Eberswalder Straße 84, 15374 Müncheberg, Germany. ISSN 1863-7329.

This review is licensed under a Creative Commons Attribution-Non-Commercial 3.0 Germany License: http://creativecommons.org/licenses/by-nc/3.0/de/. Figures that have been previously published elsewhere may not be reproduced without consent of the original copyright holders.

Because a Living Reviews article can evolve over time, we recommend to cite the article as follows:

Cédric Gaucherel, François Houllier, Daniel Auclair and Thomas Houet, "Dynamic Landscape Modelling: The Quest for a Unifying Theory", Living Rev. Landscape Res., 8, (2014), 2. URL (accessed < date>): http://www.livingreviews.org/lrlr-2014-2

The date given as $<$ date $>$ then uniquely identifies the version of the article you are referring to.

\section{Article Revisions}

Living Reviews supports two ways of keeping its articles up-to-date:

Fast-track revision. A fast-track revision provides the author with the opportunity to add short notices of current research results, trends and developments, or important publications to the article. A fast-track revision is refereed by the responsible subject editor. If an article has undergone a fast-track revision, a summary of changes will be listed here.

Major update. A major update will include substantial changes and additions and is subject to full external refereeing. It is published with a new publication number.

For detailed documentation of an article's evolution, please refer to the history document of the article's online version at http://www.livingreviews.org/lrlr-2014-2. 


\section{Contents}

1 Introduction $\quad 5$

2 Landscape processes: Current approaches $\quad 7$

2.1 Agricultural landscape . . . . . . . . . . . . . . . . . . . . . 7

2.2 Forest landscape . . . . . . . . . . . . . . . . . . . . . . . . . . . . . . . . . . . . . . . . . . .

2.3 Arid landscape . . . . . . . . . . . . . . . . . . . . . . . 10

2.4 Urban landscape . . . . . . . . . . . . . . . . . . . . . . 10

3 Landscape-model properties: Current practices $r$

3.1 Explicit versus neutral landscape models: the "spirit" of models . . . . . . . . . . . 12

3.2 Raster versus patchy landscape models: the "space" of models . . . . . . . . . . . 12

3.3 Mono- versus multi-scale models: the "scale" of models . . . . . . . . . . . . . . . 13

3.4 Modelling networks or not: the "veins" of models . . . . . . . . . . . . . . . . . 14

4 What model characteristics for what landscape type: Research priorities 15

5 Discussion: Towards a dynamic landscape theory 16

5.1 Universality behind case studies . . . . . . . . . . . . . . . . . 16

5.2 Complexity theory as a conceptual basis . . . . . . . . . . . . . . . . . . . 16

5.3 Mathematical formalism and modelling as a toolkit . . . . . . . . . . . . 18

6 Conclusion $r$

$\begin{array}{lr}\text { A Appendix } & \mathbf{2 0}\end{array}$

A.1 Neutral landscape models . . . . . . . . . . . . . . . . . . . . . . . . . . . . . . . . . . . . .

A.2 Landscape self-organization . . . . . . . . . . . . . . . . . . . . . . . . . . . . . . . . . . .

$\begin{array}{lr}\text { References } & 23\end{array}$

\section{List of Tables}

1 The four main landscape types observed on continental areas are presented in regard to the dominant properties of their respective models. . . . . . . . . . . . . . 



\section{Introduction}

Ecosystems are continuously changing in a way that is difficult to understand and to predict. Studies of climate changes (IPCC, 2007), land-use changes, biodiversity erosion (MEA, 2005), and energy management (Dalgaard et al., 2006) would strongly benefit from models aiming at better handling landscape dynamics observed on continents (and in oceans). By landscape dynamics, we imply all kinds of land-cover changes occurring at mesoscale (tens of hectares or $\mathrm{km}^{2}$ ) on Earth. By models, we imply numerical (algorithm-based) and analytical (equation-based) approaches able to handle landscape elements and their dynamics. More precisely, a landscape is usually referred to as an object assembling elements of various natures (fields, forests, buildings, hedges, roads...) in interaction, simultaneously changing through many spatial and temporal scales (Forman and Godron, 1986; Turner and Gardner, 1991).

Scientists model landscapes for at least two reasons: to better understand landscape dynamics themselves (hereafter called intrinsic needs), and to offer realistic frames to host other ecological, biological, sociological and/or physical processes (extrinsic needs) (Rounsevell et al., 2012). The role and status of models and modelling is itself an instantiation of a wider debate concerning representation and explanation (Clifford, 2007). For example, we may model urbanization and agriculture because they are two of the most important drivers of rapid changes in biodiversity worldwide (Benton et al., 2002; Cincotta et al., 2000). One of the advantages of studying landscapes as dynamic land covers is that models of this nature are not bound to some specific processes such as sectors of the economy or of biogeochemical behaviours. It helps to characterize the processes involved. Conversely, it is dangerous to infer landscape functioning on the sole basis of its observed structure (Schröder and Seppelt, 2006; Shochat et al., 2006), as the pattern-process debate reminds it to us. This paper concerns intrinsic needs mainly, and reviews terrestrial landscape models (LM) from socio-ecological as well as methodological perspectives (Collins et al., 2011).

Comprehensive studies state that agricultural landscapes today cover approximately $39-50 \%$ of continental areas (and are increasing), that forested landscapes still cover 30\% of them and are rapidly disappearing, that urban areas $(3-5 \%)$ and arid or semi-arid $(15-25 \%)$ areas are continuously growing, too (Paudel and Yuan, 2012; Vitousek et al., 1997). Numerous LM reviews may be found in the literature (Baker, 1989; Berling-Wolff and Wu, 2004; Scheller and Mladenoff, 2007; Verburg et al., 2004), but each of them is focusing on one of the four main landscape types mentioned above. Yet, these landscape types are in deep interaction on continents (Lambin, 1997; Verburg and Veldkamp, 2004). Furthermore, it is to be expected that models used for one landscape type may be useful (or at least may feed concepts) for any of the other types. Can we identify common processes behind such landscape similarities and interactions?

In this discussion paper, we address the question whether it is useful and feasible to build a comprehensive theory of landscape dynamics; and in case of a positive answer, which concepts are today relevant for this program. Hence, our objective is to show the probable unity behind the landscape diversity and to advocate the urgent need of a comprehensive theory to handle this unity. We aim at offering a critical state-of-the-art by the use of a double-entry analysis grid (matrix), focusing on the one hand on the four main terrestrial landscape types and, on the other hand, on the most relevant LM characteristics we identified. About the latter, we discuss in particular explicit or neutral models (Gardner et al., 1987; With and King, 1997), patchy or grid-based (Costanza and Voinov, 2004; Kotliar and Wiens, 1990), multi- or mono-scale models (Pascual and Guichard, 2005; Thomas et al., 2008) and landscapes with or without linear networks (Proulx et al., 2005; Pumain, 2006). We outline each case of this analysis grid by a list of associated processes and one or two examples described in more details, often taken from anthropogenic (i.e., man-made) landscapes. We then explore on the basis of this analytical grid which model characteristics would be useful for which landscape type. We did not intend to exhaustively compare papers dedicated to landscape modelling. We rather focused on theoretical and applied literature contributing to 
this first proposal of a unified landscape dynamics theory.

We finally discuss a set of proposals on the basis of the previous landscape types and model characteristics that are presumably linked, and discuss the need for a comprehensive theory to interpret landscape dynamics (Lambin, 1997), as made by some authors for modelling scales and entities with LM (Agarwal et al., 2002; Gaucherel and Houet, 2009; Haase and Schwarz, 2009; Verburg et al., 2006). We more specifically insist on anthropogenic landscapes, for the main reason that these mosaics usually superimpose in a complex way human decisions concerning already present natural processes. Such a theory should be in the continuation of landscape ecology concepts (Forman and Godron, 1986), but based on original mathematical formalisms providing new insights for the land change science (Turner et al., 2007). For example, it could be inspired from complexity approaches (Bolliger et al., 2005; Crawford et al., 2005; Solé and Bascompte, 2006). We discuss the implication of our suggestion for future research, which is needed to understand, predict and project the dynamics of these landscapes in relation to local and global environmental changes.

Table 1: The four main landscape types observed on continental areas (rows) are presented in regard to the dominant properties of their respective models (columns). The table lists occurrences that are frequent or scarce, focusing on: the presence of neutral models for each landscape type, the usual space representation, multilevel or multiscale models, the vein networks taken into account in respective models. We highlight in italics scarce intersections that are likely to be fruitful for landscape modelling and thus for landscape understanding.

\begin{tabular}{lllll}
\hline $\begin{array}{l}\text { Landscape } \\
\text { types vs } \\
\text { Model prop- } \\
\text { erties }\end{array}$ & $\begin{array}{l}\text { Spirit } \\
\text { (neutral models) }\end{array}$ & Space & Scales & Veins \\
\hline Agricultural & Regularly explored & Often patchy & $\begin{array}{l}\text { Sometimes multi- } \\
\text { level }\end{array}$ & $\begin{array}{l}\text { Often modelled, } \\
\text { of various types }\end{array}$ \\
Forested & Regularly explored & Raster & Often multiscale & $\begin{array}{l}\text { Of various types, } \\
\text { yet rarely ex- } \\
\text { plicit }\end{array}$ \\
& Scarce & Raster & $\begin{array}{l}\text { Sometimes multi- } \\
\text { level, yet not ex- } \\
\text { plicit }\end{array}$ & $\begin{array}{l}\text { Scarce } \\
\text { Semi-arid }\end{array}$ \\
& Scarce & Sometimes multi- & $\begin{array}{l}\text { Often modelled, } \\
\text { of various types }\end{array}$ \\
\hline
\end{tabular}




\section{Landscape processes: Current approaches}

Here, we choose to review the four main landscape types of continental areas, continuously interacting. In particular, the increasing human demography shows specific trends on present landscape dynamics (Lambin et al., 2001): forests landscapes are often replaced by agricultural or arid ones (Verburg and Veldkamp, 2004), agricultural landscapes are often replaced by urban or arid, partly depending on anthropogenic or climatic conditions (Figure 1). Yet, these transitions are not systematic at all. Only a few landscape transitions, such as forest shifting to agriculture, have been studied in depth up to now (Lambin, 1997; Usher, 1981), or shifts from rural to urban (Brown et al., 2013). No exhaustive description of individual models is given here, while model comparisons are helpful to emphasize their respective drawbacks and advantages (Agarwal et al., 2002; Haase and Schwarz, 2009; Mas et al., 2014; Pontius Jr et al., 2008). Instead, we present a representative list of processes concerned by each landscape type. Additionally, we systematically focus on one specific feature of each landscape type and on implementations for typical models of the domain.

\subsection{Agricultural landscape}

Agricultural landscapes are very much human-driven landscapes. Such landscapes are often studied using Land-Use and Land-Cover Change (called LUCC) models and are modelled as a selection of socio-economic and biophysical variables that act as so-called "driving forces" of land-use changes (Barton et al., 2010; Matthews et al., 2007; Verburg and Veldkamp, 2004). Land uses are simultaneously at the origin and results of land covers. Many models have shown that agricultural land covers are mainly driven by multilevel land-use processes, involving on the one hand behaviours of individuals and the upscaling of these behaviours, and on the other hand the macro-economic processes and their downscaled effects on landscapes (Thenail et al., 2009; Willemen et al., 2012). Hence, micro-economic theory and general equilibrium modelling are often combined to model agricultural mosaics driven by isolated actors such as farmers and by regional or national economic incentives (Costanza and Voinov, 2004; Lambin et al., 2000; Verburg and Veldkamp, 2004). Although biophysical factors mostly do not "drive" land-use changes directly, they can participate in land-cover changes (e.g., through climate change) and they influence land-use allocation decisions (e.g., soil quality) (Viaud et al., 2010).

Land-cover patterns are influenced at different scales of analysis by different driving forces. At the local level, this can be the local water policy or the presence of small ecologically valuable areas, whereas at the regional level the distance to a market or an airport might be the main determinant of the land-cover pattern. There are various ways to model such agricultural landscapes, depending on the interaction between biophysical and socio-economic factors that for example may influence farming practices (field and farm levels), as collective actions (community and village levels) or as governance systems (district and province levels). The wish to merge these scales in causal relationships has recently led to two broad classes of agricultural LM: the top-down approach, based on remote-sensing and other data such as the CLUE-S model (Verburg et al., 2002), and the bottom-up approach, based on local case-studies providing a refined understanding of human decisions such as the DYPAL model (Gaucherel et al., 2006b, 2010; Valbuena et al., 2010). However, we observed a limited understanding of the underlying mechanisms in the former approach and difficulties to generalize the findings due to the limited geographic coverage of the latter approach, thus justifying recent attempts to combine and even couple such approaches in landscape modelling (Brown and Castellazzi, 2014; Castella et al., 2007; Houet et al., 2010).

Many models have shown agricultural landscapes to be spatially driven by multi-level human decisions. We briefly illustrate this characteristic by highlighting a crop allocation system involving at least two successive organization levels (Castellazzi et al., 2010; Gaucherel et al., 2010; Thenail et al., 2009): the patch level and the farm level. Agricultural landscapes indeed are often 
a

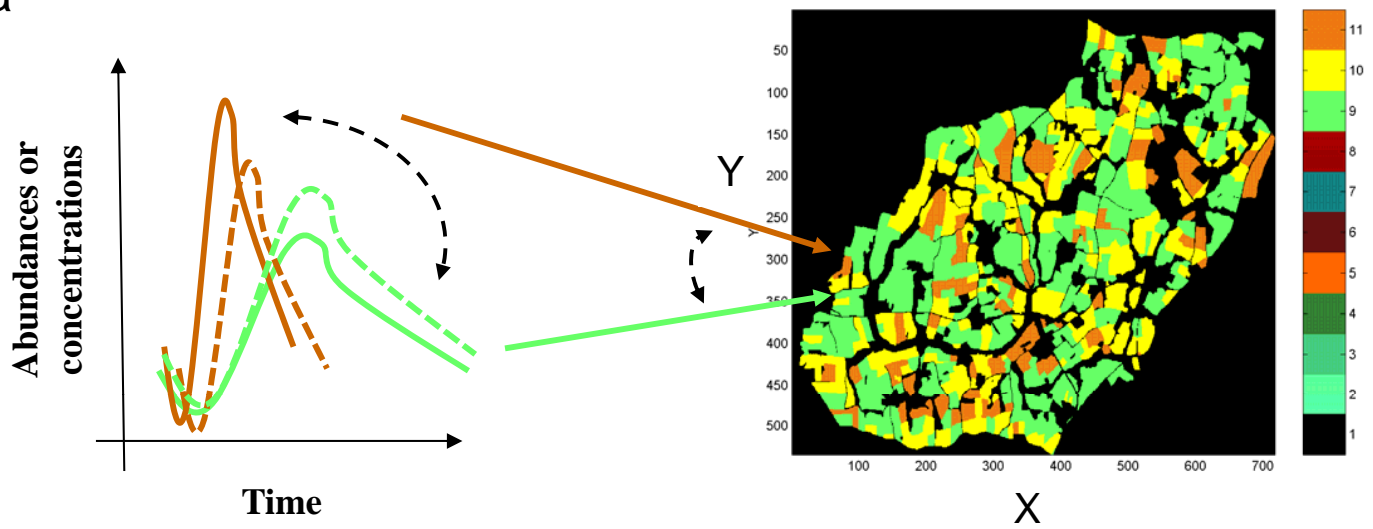

b
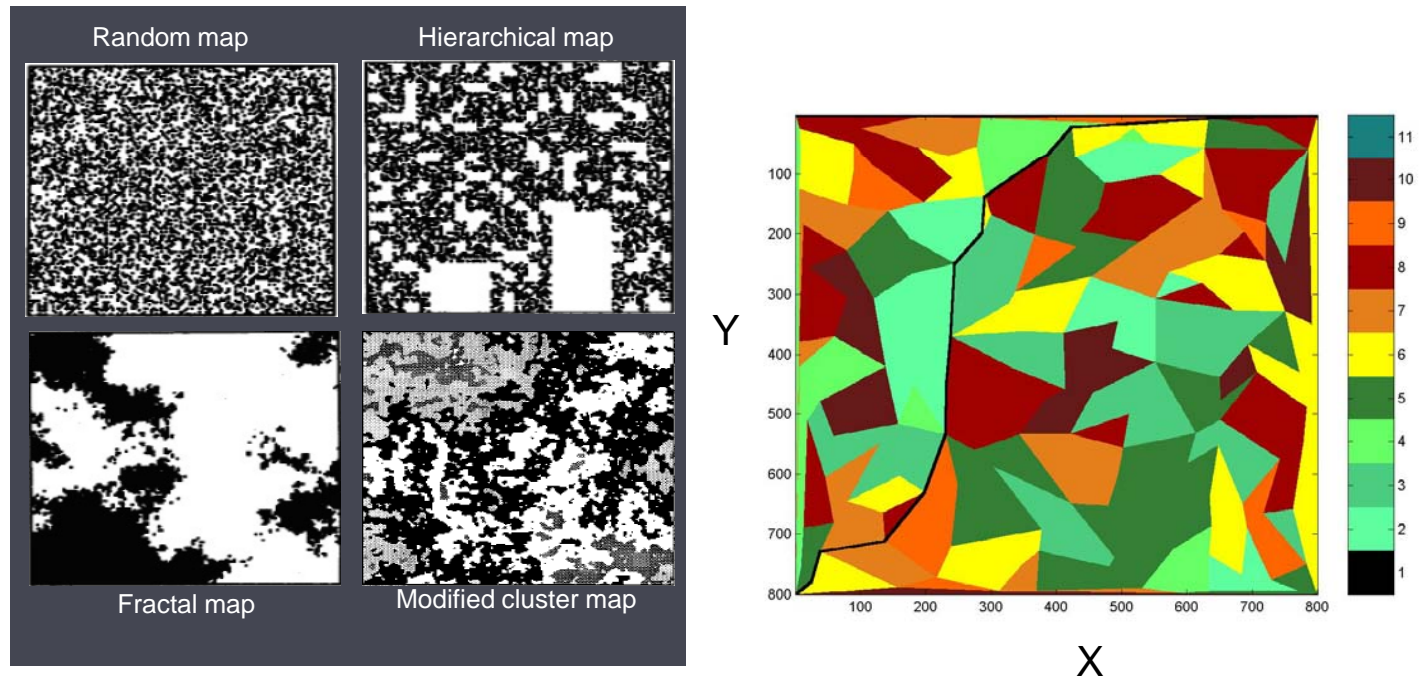

Figure 1: Illustration of the two main landscape models. There are: process-explicit models, using specific processes (a), and neutral landscape models, using random functions (b). Process-explicit models often simulate landscape structure dynamics in terms of land cover (top-right), as well as bio-ecological and socio-economical processes (top-left) hosted by these structures. In addition, these processes are interacting (dashed arrows) through neighbouring fluxes that likely modify their dynamics (dashed curves). Neutral landscape models often simulate fixed landscape structures in raster mode (bottom-left), here adapted from Saura and Martínez-Millán (2000). To study agricultural landscapes some patchy neutral models (bottom-right), associated to linear networks (in black), have recently been built on the basis of Voronoï diagrams. Colours are representing hypothetical land covers. 
composed of a wide variety of patches: crop fields, woodlots, hedgerows as well as roads, rivers and buildings, all influencing the farm property dynamics. Depending on the farm production system, the landscape is usually forced to follow a defined crop allocation at farm scale, which has been demonstrated to be the dominant driver of such human-based landscapes in temperate zones (Baudry et al., 2003).

It may be relevant to focus on the pure temporal patterns observed within or between several farms that can be modelled by Markov chain models (Le Ber et al., 2006; Usher, 1981). Conversely, spatial properties such as neighbouring fields appear to have a strong influence on the central patch studied, thus suggesting to focus on spatial as well as temporal patterns. Agricultural models have highlighted the interest of working with patchy mosaics, i.e., formed by mainly uniform, autonomous and contiguous patches, exhibiting sharp boundaries with their neighbourhoods (Kotliar and Wiens, 1990; Le Ber et al., 2006). This new interest has furthermore focused modellers' attention on the deep distinction between the landscape composition (land cover) and landscape configuration (land-cover shapes and spatial arrangements) (Li and Reynolds, 1994).

\section{$2.2 \quad$ Forest landscape}

Forested landscapes proceed from different mechanisms. At large scales, modellers usually handle forest patches (woodlots), which exhibit very different types of vegetation cover, where forest would have been considered as a single land cover in an agricultural landscape for instance (Baker and Mladenoff, 1999; Perry and Enright, 2006; Scheller and Mladenoff, 2007). Many of the first forest models were "gap models" that operate at the scale of individual trees or small forest gaps or patches (Shugart, 1984). Forest parameters under study here may be the woodlot biomass, the tree density or height, the species composition or forest age, etc.

Models may also help here to better understand the effects of fire on forests, and in particular the role of landscape connectivity on fire spread, of fuel moisture content, of time since last fire, etc. (Keane et al., 2013). Other models explore logging processes, by adjusting succession stages and transitions between communities in order to reach a particular forest state. Fire and logging are usually considered as disturbances of the landscape. In the more recent forest models, spatial interactions at and beyond the first-order neighbourhood (of an individual tree or a woodlot) are increasingly being taken into account.

The atomic entity of forested landscapes is the tree, therefore modelled by a combination of various processes such as phenology, growth and ecophysiological processes, dispersion, competition (inter- and intra-species), disturbances that may be natural (fire Finney, 1999; Keane et al., 2013, herbivores Cousins et al., 2003, pests, etc.) or human-based in the case of pruning or harvesting (de Coligny, 2006; Dufour-Kowalski et al., 2011; Kurz et al., 2000). For this landscape type, natural and human drivers are combined in complex harvesting, land-use and climate interactions.

One typical example of such processes involved in forested LM concerns seed dispersal (Cousens et al., 2008; Wang and Smith, 2002). Attempts to model seed dispersal can be described by either phenomenological or mechanistic models. The former models mainly use $\Gamma$-function kernels describing installation probability at a certain distance to the mother-plant (Clark et al., 2001; Saltré et al., 2013). The latter dispersal models explicitly simulate grain (and pollen) dispersion depending on seed downfall velocity, of the height of seed release, of the structure of the local windfield (in case of an anemochore species) or of animal movements (for zoochore species) that may promote long distance dispersal (Clark et al., 2001; Nathan et al., 2008). Models are particularly useful for highlighting the important role of long distance dispersal events to rapidly colonize new areas (Saltré et al., 2013). LANDIS is a good example of the recent generation of forest models (Mladenoff, 2004), modelling dispersal as well as many other vegetation (either natural or anthropogenic) processes. Simpler models may help to analyze a more specific process (Seidl et al., 2012; Usher, 1981). Deforestation is the most dramatic forest landscape dynamic and is, in most cases, the result of a complex causality chain, which originates beyond the forestry sector. 


\subsection{Arid landscape}

Arid and semi-arid landscapes are subject to dryland degradation and vegetation transition processes (Lambin, 1997; Rietkerk and Van de Koppel, 2008). Water availability and thus climate forcing is the main driver of such landscapes, while most studies focus on the vegetation response to water resources. Dryland degradation may start with agricultural, forestry or grazing landuse intensification and proceed with more severe degradation factors among which are found soil erosion and soil salinization (desertification). Hence, arid landscape dynamics rarely are purely natural dynamics.

Other processes linked to disturbance caused by herbivores or fires have been studied in depth to understand arid landscape dynamics and to help predict the unwanted transition from a vegetated to a desert state (Scheffer and Carpenter, 2003). Drivers here are climate change impacting primary production of vegetation (Sankaran et al., 2005), as well as socio-political mechanisms leading to a "pressure of production on resources" (Barton et al., 2010; Krol and Bronstert, 2007). In most cases, we observe a somewhat complex interaction between natural and anthropogenic processes, such as in the desertification phenomenon (Lambin, 1997; Lejeune et al., 2002). Many models help to address the questions why, where and when such arid landscape changes take place.

Some recent studies have explored a specific case of arid landscape dynamics involving binary states (vegetated and non-vegetated states) and two opposing forces of landscape shaping. It has been shown in particular that regular patterns may be the result of a competition force slowing down the vegetation colonization and a facilitation force favouring the same colonization trend (Couteron and Lejeune, 2001; Lejeune et al., 2002). Competition for water resource through roots and facilitation against solar heat through the canopy act at different spatial scales, thus generating a wide panel of regular patterns (spotted or banded patterns, etc.).

Other studies at higher scales have shown that the size distribution of vegetation clusters in undisturbed plots follows a power law distribution (Scanlon et al., 2007): most patches of vegetation have a small size, but a few of them have a very large size. Such self-organization pattern (i.e., landscape organization exhibiting a self-similar property, see Appendix A.2) seems to be the result of internal dynamic processes driven by local interactions, yet sometimes controlled by external factors such as precipitation (Rietkerk and Van de Koppel, 2008; Sankaran et al., 2005). Such landscape functioning is still under debate and it is not yet clear how regular and self-similar patterns differ. As evidenced by the previous references, models in this landscape type are still often theoretical models.

\subsection{Urban landscape}

Similarly to agricultural landscapes, urban or periurban landscapes are mostly driven by humans (Berechman and Small, 1988; Berling-Wolff and Wu, 2004). The historical development of urban growth models are rooted in transportation and land-use planning. Early models postulated that the interaction between two cities and within a city varied directly with the size of the (two) city (cities), i.e., its demography, and inversely with the square of the distance between them (or the distance to its centre) (Foot, 1981; Lowry, 1964). The urban area was represented as a transport network and the flow and assignment of trips to the transport network modelled; later, more complex trips (home-work journeys) have been modelled and validated, even taking into account transport network congestion. In parallel, the idea emerged that trips and traffic in the city resulted mainly from decisions at the individual household level. At this stage, public policy impacts on household dispersion, employment constraints, urban agglomeration economics (and real-estate prices) and other land-use planning are analysed in various urban growth models (Gusdorf and Hallegatte, 2007; Gusdorf et al., 2008).

As a relevant process in urban LM, we would like to consider urban growth with two different models. Interestingly, some cellular automaton models have emphasized the way in which locally 
made decisions may lead to global self-organized urban patterns which are rarely, if ever, in equilibrium (Viguié et al., 2014). For example, diffusion-limited aggregation models have been developed to handle rapid disequilibrium growth often due to the emergence of suburbs (Batty et al., 1989; He et al., 2013). Recent models focus on economics of agglomeration or ecological energetics, the flow of goods and resources in the city to better explain such disequilibrium. Cellular automata combining ideas of evolution, self-organization and fractal geometry enable to calculate transition potentials mimicking land-use changes by agents' behaviours (White and Engelen, 1993). These models have been found in good agreement with observations. Similarly, the FRACTALYSE model extends Christaller's Central Place theory according to a fractal (self-similar) principle, i.e., areas with smaller and smaller aggregated central places (Christaller, 1972; Thomas et al., 2008). Such an approach indeed, enables optimizing urbanization processes by minimizing the use of places and buildings nearby places already occupied.

The concept of urban systems (i.e., multi-city urban networks) is complementary to that of urban growth and several models have documented and interpreted this concept (Pumain, 1989). After early models based on the central place theory, a second period of landscape modelling made a more explicit use of the networks, both in analyzing communication or migration flows between cities and by suggesting that networks were more efficient and more democratic forms of organization than hierarchies (He et al., 2013; Proulx et al., 2005; Pumain, 2006). Networks of innovation diffusion, inter-city migratory fluxes, urban competition, socio-economic trajectories of cities and comparative urban dynamics have become again implicit, but can help understand urban systems (Berling-Wolff and Wu, 2004).

\section{Landscape-model properties: Current practices}

Landscape models (LM) as defined here should not be confused with "landscape analysis models" aiming at analysing a spatial structure at landscape scales (Müller and Steinhardt, 2003). Instead, LM are dedicated to simulation of landscape change and dynamics. The previous section emphasises that many dynamic LM have been reviewed in the literature, concerning agricultural, forest, arid and urban landscapes (Berling-Wolff and Wu, 2004; Scheller and Mladenoff, 2007; Verburg and Veldkamp, 2004). LM mentioned in this paper are merely a sample selected to highlight some of the most important features of landscape modelling to explore some of the key challenges facing those who build and use LM. To be exhaustive, this section should also address considerations about the time management of models (Degenne et al., 2009), about the 2D-3D representation of space in LMs (Gaucherel et al., 2010), and many others. The time and spatial dimension challenges are urgent to improve our understanding of external needs such as biogeochemical processes, for example.

Scientific models pertain to various epistemological modes (Levins, 1966). They often serve an objective of comprehension through hypothesis tests and inference processes; they also help to define prospective objectives thanks to scenario elaboration and decision support tools; they finally offer a methodological objective by helping to define experiment protocols, by performing in silico experiments, by developing new algorithms and equations to fulfil a scientific questioning. In addition, another advantage of models is to integrate (to gather) knowledge into a coherent framework. We are not discussing here other topics concerning landscape modelling such as data calibration, validation, observation/simulation, comparison or sensitivity analyses. They are indeed critical in this debate about landscape modelling, but this would need another full-paper and has been well discussed in the literature (Jørgensen and Bendoricchio, 2001; Mas et al., 2014; Paegelow et al., 2013). 


\subsection{Explicit versus neutral landscape models: the "spirit" of models}

The first and probably main dichotomy observed in LM concerns process-explicit versus neutral models. Process-explicit models simulate landscapes by implementing one or several specific processes, such as in most of the previously mentioned models (Costanza and Voinov, 2004; Gustafson, 2013; Seidl et al., 2012; Verburg et al., 2004) (Figure 1a). Instead, neutral models are simulating landscapes with similar patterns and statistical properties without any process implementation (Gardner and Urban, 2007; With and King, 1997) (Figure 1b). Such models are more or less neutral, depending on the more or less extensive use of random functions to generate the pattern (see Appendix A.1 for details). Neutral LM offer some kind of null-hypothesis tests translated into the landscape dynamics topics. They help to answer the generic question: Does a random (or almost random) function simulate observed patterns (or not) and, more rarely, observed dynamics (Caillault et al., 2013)? If so, it is maybe not necessary to combine complex landscape generation processes to interpret observed landscapes (Gaucherel et al., 2006a; Saura and Martínez-Millán, 2000). Furthermore, if so, it becomes possible to model new virtual landscapes, dedicated to intrinsic as well as extrinsic needs already mentioned.

We have earlier detailed the kind of processes that are explicitly taken into account for LM, either of biophysical or socio-economical nature, and often both (Willemen et al., 2012). A promising way of combining these various landscape processes certainly pertains to the use of model platforms in order to efficiently build models dedicated to landscape topics (de Coligny, 2006; Dufour-Kowalski et al., 2011; Gaucherel et al., 2006b) (Figure 2a). Another promising opportunity is that of Domain-Specific Language (DSL) (Degenne et al., 2009; Fall and Fall, 2001). DSL are languages adapted to a specific target, such as modelling a broad class of landscapes, and sharing various methods and knowledge for this goal. They are almost all process-explicit models, with the exception of the RULES platform dedicated to neutral models (Gardner, 1999).

\subsection{Raster versus patchy landscape models: the "space" of models}

Another important dichotomy among LM, often mentioned but rarely discussed, concerns the type of spatial representation chosen to be implemented in the model. Most LM handle raster mode, i.e., grid-based or pixel-based, mosaics (Costanza and Voinov, 2004; Saura and Martínez-Millán, 2000), because pixels are easier to manipulate than the various objects found in the vector mode (i.e., polygons, polylines, points...) (Degenne et al., 2009; Gaucherel et al., 2006a). Yet, most landscapes, if not all, are patchy in the sense that they are composed of patches (polygons) that are considered uniform relatively to their main attribute (often land cover), with sharp boundaries separating them from the contiguous neighbours (Forman and Godron, 1986; Kotliar and Wiens, 1990). Such landscapes are often called categorical, as they suppose land-cover categories, with discrete states of patches. In a sense, landscape modellers realize that landscapes are often discontinuous and may be less efficiently handled by the classical tools developed for several decades, such as point-pattern processes, interpolations as Geostatistics, etc. New surface-pattern analysis and modelling tools are now able to handle highly non-stationary spatial structures (i.e., with variable statistical moments) (Gustafson, 1998; Li and Reynolds, 1994; Tischendorf, 2001). We list here a panel of advantages to model dynamic landscapes with patchy mosaics.

1. Realism - Among all advantages, the most convincing is certainly that patchy landscapes are more realistic. This argument is quite obvious for agricultural and urban mosaics, i.e., human-based landscapes (Forman and Godron, 1986; Kotliar and Wiens, 1990), but is still relevant for large forested and arid mosaics too, as we have seen that they often exhibit regular (and thus patchy) patterns, due to discrete soil, topography or climatic properties. Furthermore, this representation highlights existing boundaries between landscape elements. We argue here that the patchy representation, particularly suited for man-made landscapes, 
may suit well to most natural landscapes too, considering their natural boundaries (Henne et al., 2011; Moustakas et al., 2009; Viaud et al., 2010).

2. Complementarity - Patchy landscape simply is a new approach to study this object, thus offering an independent and potentially innovative way of studying the same object. Such independent ways of study have often been mentioned as useful to cross-check scientific interpretation. Manipulating polygons or polylines indeed suggests working with other unitary/single elements, computing and analytical methods, other topologies, etc. (Degenne et al., 2009; Mackey, 2000). For example, polygons have at least as many neighbours as their numbers of edges, while pixels always have eight neighbours, presenting the same directions. This difference partly explains difficulties to handle vector mode objects, but also highlights the richness of this approach.

3. Qualitative view - A patchy approach is often more intuitive and more rapid than pixel-based approach once implemented, because it handles a single object (e.g., a polygon) instead of handling a list of non autonomous and/or non independent pixels being linked to artificially create the uniform polygon studied. As a corollary, the patchy approach enables working with much larger landscape extents or much more rapidly for a similar extent. Yet, possible drawbacks concern the need to model landscapes in a more qualitative view that is not always easy to handle (e.g., distance related questions such as pollen or gene diffusions).

4. Property control - Interestingly, the patchy concept finally helps to understand the difference between the landscape composition (land cover) and the landscape configuration (patch arrangement) (Li and Reynolds, 1994). In a grid-based approach, both are mixed and handled in a simultaneous way, because changing a pixel state changes its land cover simultaneously to the land-cover pattern with its neighbours. While landscape composition and configuration are not fully independent in a patchy approach, they appear to be sufficiently differentiated to understand whether the studied landscape process concerns purely attributive changes, such as agricultural successions (Castellazzi et al., 2008; Verburg and Veldkamp, 2004), or is also modifying geometrical and/or topological changes, such as in urban systems for example (Pumain, 2006).

5. Object-oriented view - Similarly to remote sensing transition between grid-based and objectbased detection, it is relevant in LM to manipulate objects (Flanders et al., 2003). The patchy approach helps to dissociate objects within the landscape and to develop specific dynamical processes for them. Instead, a pixel is changing continuously from a crop field, a forest, a household, depending on probability transitions and thus is losing its nature all the time (Usher, 1981). Hence, patchy landscapes that are rather widespread and intuitive would possibly contribute to federate attempts directed towards the search for a general LM framework.

\subsection{Mono- versus multi-scale models: the "scale" of models}

LM often are multiscale, in a sense of including objects spreading over continuous scales or of including processes spread over several discrete organization levels. Multi-level models consider landscapes with two or more discrete organization levels such as temperate agricultural landscape processes mainly based on crop field rotations and farmer decisions. Other levels than farmers (villages, governments...) are often useful in modelling complex human-based landscapes. A more continuous view of scales, quite relevant in the case of natural landscapes (Pascual and Guichard, 2005), would probably be less appropriate and more difficult to implement in humandriven landscapes, due to our perception of discrete levels of actors in landscapes. It has been shown that crop allocation at the farm scale is responsible for most agricultural landscape patterns 
(Benoît et al., 2012; Houet et al., 2010; Rizzo et al., 2013; Thenail et al., 2009). Studying the sole crop rotation is a fruitful approach when computed with Markov chains (Le Ber et al., 2006), although we cannot ignore the spatial autocorrelation caused by farm management (Baudry et al., 2003). This observation remains relevant for higher organization levels such as regional decisions, but today models rarely account for such multiscale/multilevel manipulations.

Vegetation cover in forested or arid ecosystems also shows various scaling behaviours. In particular, self-similar relationships between vegetation cluster size (scale) and their number (count) can define self-organized patterns of forested studied landscapes (Scanlon et al., 2007). Several models such as in arid or forested areas have shown that local interactions may exhibit scaling laws over a wide range of conditions in arid areas, thus providing examples illustrating the criticality theory, i.e., discontinuous transitions between vegetated and non-vegetated zones (Pascual and Guichard, 2005; Rietkerk and Van de Koppel, 2008). Yet, such behaviours (Solé and Bascompte, 2006) are not convincing: first, they are not robust over scales (they concern only few orders of magnitude); second, they are not fully understood (for example the scaling exponent cannot be predicted by the originated processes); third, they are phenomenological and should still be related to the ecological processes involved (Gustafson, 2013); and fourth, if some processes (such as preferential attachment) have shown self-similar behaviours, it has not been proved that other processes would not succeed in doing so. In other words, this self-organization approach is close to a neutral model, but probably not fully appropriate for LM, as we think it will probably not provide in depth processes to understand landscape functioning.

\subsection{Modelling networks or not: the "veins" of models}

Agricultural and urban systems exhibit physical or more abstract linear networks in dynamic landscapes (Berling-Wolff and Wu, 2004; Turner and Gardner, 1991). Agricultural areas are for example characterized by the so-called "blue veins" constituted by river networks, and by "green veins" such as hedgerows and other grass margin networks that all have strong effects in the landscape generation and functioning (Thenail and Baudry, 2004). Fields and farms indeed are managed according to the islet they belong to, as farmers naturally follow these networks for defining their boundaries. Other networks (veins) are frequently found in rural areas, such as roads, dyke or ditch networks that may structure the landscape as well. Models have for example shown how a dyke network can influence the animal population viability it is hosting (Retho et al., 2008).

Above all, the field mosaic itself is sometimes modelled by the use of a network, considering that each patch is characterized by a gravity centre (or a summit of a graph) and is linked to its neighbours (with the edge of the same graph) (Gaucherel, 2008; Le Ber et al., 2006). Such linear networks can help to develop new analyses and to model tools as their objects have specific properties (Proulx et al., 2005; Strogatz, 2001). They grow or divide in specific patterns and topological dynamics that are very different from point-patterns or surface-patterns already mentioned. Urban landscapes highlight in particular the role of hidden networks such as communication and transport networks. Phone, electric or energy (e.g., gas) networks may strongly structure the emergence of new households in suburban areas (Berechman and Small, 1988; Pumain, 2006). Transport networks, such as roads, railroads or tracks are also a strong constraint in the landscape dynamics (Forman and Godron, 1986). 


\section{What model characteristics for what landscape type: Research priorities}

The appropriateness of model characteristics for modelling different landscape types has been rarely studied in detail. To combine the previous sections dedicated to landscape types and to LMs should help us to define research priorities in this field (Figure 1). For example, we mentioned that patchy models simulate agricultural landscapes, that neutral models are used to study forested landscapes, that multiscale models are applied to arid landscapes, and that urban landscapes are often modelled by taking into account various networks. Such approaches are not exhaustive. We question here whether further developments of the previous model characteristics for new landscape types would open fruitful and complementary avenues to the field.

1. Neutral models - Neutral models, acting as null-hypothesis tests, are useful to identify mechanisms responsible for the observed landscape pattern or, rather, for refutation of absent mechanisms (Gardner and Urban, 2007; With and King, 1997). It is often discussed how a specific process is able to generate a specific pattern, but it is more rarely tested how random or almost-random processes are not able to do the same.

2. Patchy models - A patchy approach is almost always possible to use, either according to some segmentation criteria or empirically and usually leads to a new conception of the studied landscape. Indeed, to use uniform patches with sharp boundaries between them is equivalent to discretize space in a specific way, radically different to that of more regular continuous or periodical representations (Gaucherel et al., 2006a; Paudel and Yuan, 2012). This is obviously the result of approximations within each patch, never perfectly uniform, but this approach also enables better taking into account various "singularities" observed in real landscapes. Singular presences are common in human-driven landscapes, as humans usually differentiate land covers and avoid managing fuzzy boundaries. It is also relevant for natural landscapes (Levin et al., 1993), in particular at higher scales, when smoothed (geological, lithological or hydrographical) boundaries between land covers are progressively reduced to a narrow line (Moustakas et al., 2009; Viaud et al., 2010). Fluxes or organism movements can be stopped at or redirected along these lines of highly irregular (non-stationary) zones, thus leading to new behaviours of involved ecological processes (Forman and Godron, 1986; Turner and Gardner, 1991).

3. Multiscale models - Multilevel and multiscale LM are being increasingly studied, but could be further explored in new contexts. While it is often easier to work at only one or two scales to simulate a pattern, the frequent roles of lower and higher scales have been shown in these pattern generations (called emergent or immergent). When scales are considered as discrete levels, the hierarchy theory has proposed a heuristic approach for many ecological and environmental studies (O'Neill et al., 1986; Willemen et al., 2012). When scales are continuously successive, many concepts such as self-similarity (Pascual and Guichard, 2005; Scanlon et al., 2007; Solé and Bascompte, 2006) or multifractality, and many tools such as geostatistics, wavelet transform (Grossman and Morlet, 1984), or local convolutions (Gaucherel et al., 2008) have been developed in order to describe and sometimes to model them. Hence, such multiscale LM can be expected to flourish in the future.

4. Network models - Finally, linear networks are of a great importance in landscape dynamics. There are several reasons why they have not been studied in a similar extent to that of other landscape features: i) they are rarely the central object of landscape studies, far behind crop fields or tree stands for example (Forman and Godron, 1986); ii) reliable mathematical tools to handle networks such as graph theory have been considered only recently in environmental 
sciences (Strogatz, 2001); iii) many ecologists were not sufficiently aware of the role of these linear elements before some studies showed how landscape structures are constrained by them (Proulx et al., 2005). Studying relationships between a landscape and the networks that inhabit it (e.g., green veins, blue veins, or roads) will probably lead to new discoveries. In case of urban or agricultural mosaics, landscapes may sometimes be reduced to the sole network that is carrying most of the landscape information (Thenail and Baudry, 2004). Further, if we widen our considerations from linear networks to every kind of network, each landscape element can be considered as the node of a network, related to its neighbours by the network edges. Such topological network may be rich in information and interesting to study as such, opening new pathways to model landscapes (Gaucherel et al., 2012).

\section{Discussion: Towards a dynamic landscape theory}

\subsection{Universality behind case studies}

On the basis of the landscape and model characteristics summarized in the previous sections, we suggest that there exists a profound unity between landscape-modelling case studies. Patchy structures, network roles and multiscale behaviours justify searching for a unified view of dynamic landscapes. The landscape concept is generic and the heterogeneity concept is universal. The central paradigm of landscape ecology is that the spatial structure of a landscape has an effect on the underlying ecological processes (Forman and Godron, 1986; Turner and Gardner, 1991). Some properties of the landscape such as heterogeneity, connectivity or fragmentation strongly influence the exchange and flow of organisms, matter and energy between the different components. From the start, deciphering the structural and the functional aspects of connectivity has been a challenge to landscape ecologists (Tischendorf and Fahrig, 2000) and discussions are still on-going. Moreover, this branch of ecology insists on the importance of scales and integration of processes (Dungan et al., 2002).

Multiscale and network concepts, for example, are widespread and have recently appeared in the literature for a wide range of specific landscape studies (Caillault et al., 2013; Gaucherel, 2008; Thenail and Baudry, 2004). They offer opportunities for renewing the usual landscape ecology concepts (e.g., heterogeneity) that are no longer sufficient to understand complex and dynamic systems. Lambin mentioned that "the most fundamental obstacle to progress in the understanding and prediction of human impacts on terrestrial ecosystems lies in the lack of comprehensive theory and land-use changes" (Lambin, 1997). This remark, made for human-driven landscapes, may also be addressed to more natural landscapes: Do we today have at our disposal a comprehensive theory of land-cover dynamics? (Bolliger et al., 2005). We have therefore to search for a common theoretical framework proposing coherent concepts and adapted formalisms to improve our understanding and modelling of landscape dynamics. From a more practical point of view, the UML (Unified Modelling language) emerged to provide a simpler and more universal language to model, but it remained poorly used in landscape modelling (Degenne et al., 2009). The theoretical statement should not conceal the important role of data acquisition, without which no LM could exist, and the role of model application and validation in specific sites and dates. We are also conscious of the limits of describing ecological processes from landscape patterns in this way (Schröder and Seppelt, 2006). A theoretical framework for all types of terrestrial ecosystems, if any, should bear in mind such a debate and offer generic tools to bridge the gap between them.

\subsection{Complexity theory as a conceptual basis}

Awareness that a certain complexity was present in most landscapes has led to a holistic approach to landscape (Gallagher and Appenzeller, 1999; Looijen, 1998). The theory of complexity has shown 
that the state and behaviour of certain systems does not result from the simple linear combination of the state and behaviour of its separate parts. Thus new properties are seen to emerge, which originate in the non-linearity and non-equilibrium of these systems (in thermodynamic terms). The study of these complex systems suggests holistic strategies that apply to landscape modelling as the landscape is a complex object (Bolliger et al., 2005; Saltré et al., 2013), which often has complex dynamics (Bürgi et al., 2004). It shows emerging behaviours/patterns that are the result of complex interactions, such as diffusion or dispersal, crop allocation system or land-cover transition (time patterns), heterogeneous and multiscale growth of areas (spatial patterns), between its elementary/single constituents. If such processes seem very different, they may all appear for various situations and highly different landscape types. It is thus relevant to study them in unusual situations in order to trigger a possible unity hidden behind landscape dynamics of distinct types.

Landscapes are dynamical, a property that often remained understudied compared to the landscape pattern in itself. Some diachronic works intended to compare successive dates of these patterns (Kolb et al., 2013; Mackey, 2000; Paudel and Yuan, 2012), but it was a preliminary task compared to complex, superimposed, multiscale and long term dynamics that are at play in every landscape. We now need to analyse these dynamics for themselves and ask related questions: Is a landscape stationary (i.e., with constant statistical moments) or does it present some discontinuities in time (Gaucherel et al., 2012)? Is a landscape dynamic chaotic? Is it ergodic (i.e., with the same behaviour averaged over time as averaged over space)? What are its asymptotical states, if there are some (Gaucherel, 2011)? Does the landscape gather some conflicts (i.e., opposed changes of the same unit), for example between dynamics operating at different scales? We today need a conceptual shift to address these new issues.

Self-similar approaches in particular are in the vein of complexity theory, as they manage multiscale, non-linear and often out-of-equilibrium systems (Pascual and Guichard, 2005; Solé and Bascompte, 2006). Neutral and multiscale models are recent attempts to detect and quantify self-organization, while patchy mosaics and networks are well adapted to such attempts, too (He et al., 2013; Paudel and Yuan, 2012). This explains why several scientists have begun to adapt these approaches to landscape studies (see Appendix A.2 for details), as mentioned in the previous section. Patchy and network systems are complex as they handle non-linear behaviour in space and time, for fluxes or movements that they shelter (Gaucherel, 2008; Proulx et al., 2005). Hence, the four model characteristics detailed in this paper are well adapted to further develop a complex and unified view of terrestrial landscapes. They are probably not yet exhaustive, as specific temporal dynamics, driving forces, and spatial interactions of neighbouring or level of integration may be explored in more detail and compared between landscapes.

To go a step further, it has been mentioned that self-organization is a kind of optimization of the structure (D'Souza et al., 2007). We propose here the hypothesis that every landscape is a structure optimized to better use (dissipate) its incomes (of energy and matter). Neutral LM may help to test this working hypothesis, by assembling various local and path-dependent processes (Brown et al., 2005), i.e., depending on the previous time step (or steps) only, acting on patches, linear networks and point-patterns, and being finally optimized in order to fulfil the various constraints imposed to the landscape. Some recent illustrations of such landscape optimisations may be found in the literature (Gaucherel, 2011) and we recently explored this issue with the optimal control theory (Whittle, 1996) to summarize a landscape by defining its Hamiltonien function. This attempt proposes an appealing framework to improve our description of very different (yet, with common properties) landscapes. Such work is in the continuity of landscape ecology, as landscape heterogeneity may then be interpreted as a consequence of such optimization of land uses and/or land covers. In a sense, the landscape exhibits some properties close to that of living organisms, with changing, scaling, emerging and stabilizing patterns (heterogeneity properties) depending on its driving forces. 


\subsection{Mathematical formalism and modelling as a toolkit}

To imagine new concepts is a prerequisite for developing a new dynamic landscape theory, but it will be necessary to simultaneously develop a mathematical formalism, in order to generically handle these concepts over a wide range of landscape types. There are very few attempts, to our knowledge, to formalize landscapes in terms of equations. The literature provides powerful Markov chains to manage landscape composition (Tepley and Thomann, 2012), under stationary and sometimes first order neighbourhood hypotheses (Le Ber et al., 2006), while reaction-diffusion equations are sometimes able to manage landscape configuration, for natural and non-patchy lattices (Couteron and Lejeune, 2001). Yet, the coupling of landscape composition/configuration is rarely managed and agricultural or forested mosaics have not been set in equations. It is today a challenge for example to mathematically describe spatial autocorrelation of patchy and highly discontinuous patterns (Gaucherel, 2011; Levin et al., 1993), in order to reveal hidden processes, to integrate them, to determine asymptotical behaviour or to predict landscape behaviour in alternative conditions. Here are the urgent issues of this formalization objective. Furthermore, the dynamics of such structures are still far from being mathematically described. For example, it is a challenging question to understand whether some landscapes are at equilibrium or not. The self-organization or optimization concepts have the advantage of offering coherent formalisms to handle various landscape types such as relatively continuous patterns. Statistical mechanics and optimal control theory (Whittle, 1996), may fulfil this requirement to open the way to holistic studies of landscapes.

A recent approach based on formal grammars, and in particular those related to graph rewritingrules opens another track in this direction (Gaucherel et al., 2012, 2010), especially for highly non-stationary (discontinuous in space and time) mosaics. Models based on formal languages, such as L-systems used in linguistics and biology (Lindenmayer, 1968a,b), develop objects using grammar-linked components to simulate automata: landscape patches are considered as words whose dynamics are described by a succession of rules that a grammar helps to formalize. It has been demonstrated that most patchy landscape compositional as well as configurational changes may be formalized by a combination of eight rules only: a landscape patch rotation, merge, split, dilation, erosion, appearance, disappearance and no change (Gaucherel et al., 2012, 2010). This so-called landscape language has a flavour of universality and appropriately illustrates the possible unification of a wide range of landscape dynamics, be they patch, linear network or natural gradient changes.

Such kind of formalisms has the potential to widely spread into environmental disciplines. In a sense, they offer bottom-up approaches that require symmetrical top-down approaches, such as global optimization procedures, to complete our understanding of landscape dynamics (Castella et al., 2007; Houet et al., 2010). This is why it is still important to develop mechanistic models and to model contingent and specific processes (Gustafson, 2013), with local and Markovian rules. As a corollary, another challenge for landscape dynamic studies consists in developing model designs able to conciliate the rich ecological and socioeconomic knowledge we have with the requirement for formal models amenable to generalization across landscape types. Adequate methodologies such as platforms and domain-specific languages are at present under development to help this purpose (Figure 2b) (de Coligny, 2006; Degenne et al., 2009; Fall and Fall, 2001; Gaucherel et al., 2012). 


\section{Conclusion}

Continents are undergoing rapid change. At fine scales, terrestrial landscapes are rapidly changing too, whatever they are, agricultural, forested, urban or arid. In addition, these four main landscapes are continuously meeting together in space and time, shifting from one of the previous types to another, under natural (climate change) and/or human driving forces (Figure 1). To benefit from a relatively unified theory of such landscape dynamics would help to better understand each of these landscape types as well as each observed landscape type transition. We have discussed here only intrinsic needs to understand the landscape object, but such a review can obviously also serve extrinsic needs: for example, population dynamics, fire and pest spread, human production systems, climatic influence are environmental processes that would all benefit from an improved landscape modelling. Such improvements in dynamic landscape theory and modelling would greatly facilitate the (weak or strong) coupling between terrestrial landscapes and species and would serve climate change and biodiversity assessments.

We are now starting to have powerful models to manipulate various landscape dynamics and to better understand their functioning. Landscape research offers several interesting concepts to understand landscapes, but such concepts are insufficiently adapted to recent modelling approaches. The intrinsic dynamic properties of landscapes, their multiscale properties, the network and patch interactions they inhabit are difficult to manage by the simple use of heterogeneity and fragmentation notions. To improve as well as to harmonise current landscape modelling, we propose in this review and discussion paper to explore several actions: i) to develop explicit process-based models, handling both natural and human driving forces, simultaneously to neutral LMs; ii) to favour the interaction of various landscape type models; iii) to develop patchy, network (of various types) and multiscale modelling; iv) and above all, to develop a coherent theoretical framework of dynamic landscape, on the basis of new and powerful neutral models and mathematical formalisms.

\section{Acknowledgements}

We thank C. Godin for having provided the Figure 2a. We warmly thank A. Cambien, A. Banos, J. Baudry, P. Couteron, and D. Lo Seen for their advice during the process of writing this paper. This synthesis was developed in the course of several projects funded by the Agence Nationale de la Recherche (projects "BiodivAgriM" and "INC", ANR-biodiversité 2007, project "STAMP", ANRblanc 2007). We are thankful to anonymous reviewers for their helpful comments and suggestions on an earlier draft. 


\section{A Appendix}

\section{A.1 Neutral landscape models}

Ecology is increasingly using "virtual" landscape modelling to evaluate the links between ecological processes and the spatial and temporal patterns they produce. Neutral landscape models, in particular, were designed to generate a landscape in the absence of a studied ecological process (Gardner et al., 1987; Saura and Martínez-Millán, 2000). Unlike explicit LM that would simulate dynamic functions and relations between landscape elements, neutral models do not intend to produce the spatial pattern of any particular observed landscape. Neutral models deal more precisely with one or several characteristics of composition and configuration of real landscapes (Gaucherel et al., 2006a; With and King, 1997). These models may belong to most of the above-mentioned landscape types (agricultural, forested, arid or urban mosaics). After comparisons with observed landscapes, spatial landscapes and structures simulated by neutral models can discriminate between influences likely to be caused by random (i.e., neutral) rather than real structures. Their contribution to landscape ecology has been extensive: development of spatial indices to describe landscape configurations, forecasting of configurations essential for ecological phenomena, definition of connectivity, understanding of landscape influence on animal species or seeds, development of a generic model of spatial complexity, identification of ecological consequences of spatial homogeneity. Many ecological applications for neutral models are found in studies on the dispersion and abundance of animal populations, forest fires or biodiversity (With and King, 1997).

There is a gradation of virtual landscapes, from the pure neutral model up to the almost explicit model (Figure 2). Landscapes simulated by neutral models are often pixel matrices (called raster mode) for which a land cover is associated to each pixel. In the simplest neutral model, random distributions of the two present classes are performed by associating each pixel with a probability of belonging to one of the classes. This simple model only constrains class densities (i.e., composition) and not their spatial distributions. The absence of spatial correlations in such models does not allow accounting for the complexity of real landscapes (Saura and MartínezMillán, 2000). Although rudimentary, the random model has identified characteristics such as the critical value of the class probability beyond which certain properties (e.g., connectivity) of a simulated landscape are drastically different. More sophisticated, some configuration models also define a directional adjacency matrix $Q$. The $Q_{i j}$ elements translate the probability of a pixel belonging to type $i$ being adjacent to a pixel of type $j$, with adjacency possibly defined according to direction and distance (Gardner, 1999). These models can be refined by the modified random cluster method, which controls the shapes of simulated classes, by aggregating pixels together (Saura and Martínez-Millán, 2000). Many other neutral LMs have been proposed, for example on the basis of an iterative process changing some pixel classes, and thus leading to hierarchical or fractal patterns (Figure 2b).

All neutral models presented here deal with landscape considered as a continuous entity in raster mode, where the pixel is an autonomous (yet not independent) entity. Several ecological studies, however, need to represent landscape with a patchy map in which areas are considered homogeneous from the point of view of the ecological process studied (Kotliar and Wiens, 1990; Levin et al., 1993). This becomes crucial in anthropogenic landscapes and those marked with linear networks (roads, rivers, hedgerows, etc.) or field limits. For this purpose, new neutral LMs have been developed (Gaucherel, 2008), which sometimes use a Gibbs algorithm to select patch classes or to draw linear networks. Furthermore, neutral LMs appear increasingly relevant as a basis to build a coherent theoretical framework for dynamical landscapes. By offering a null-hypothesis test, they help to discriminate between ecological processes and random functions. By handling more or less simple statistical equations to describe landscapes, they offer opportunities to capture patterns and/or dynamics within parsimonious and coherent formalisms. 
a

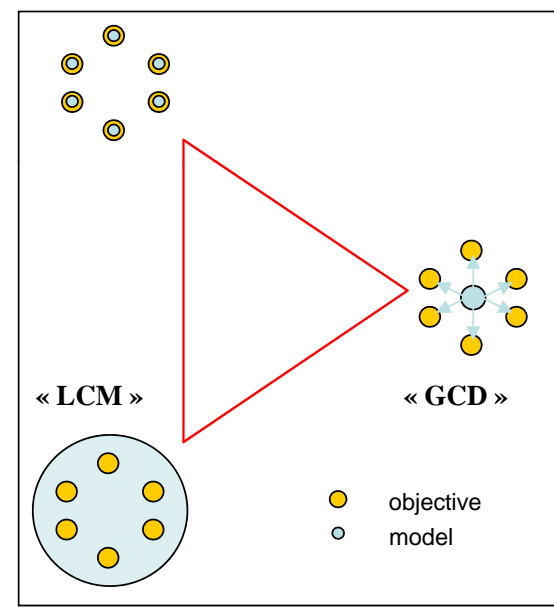

b

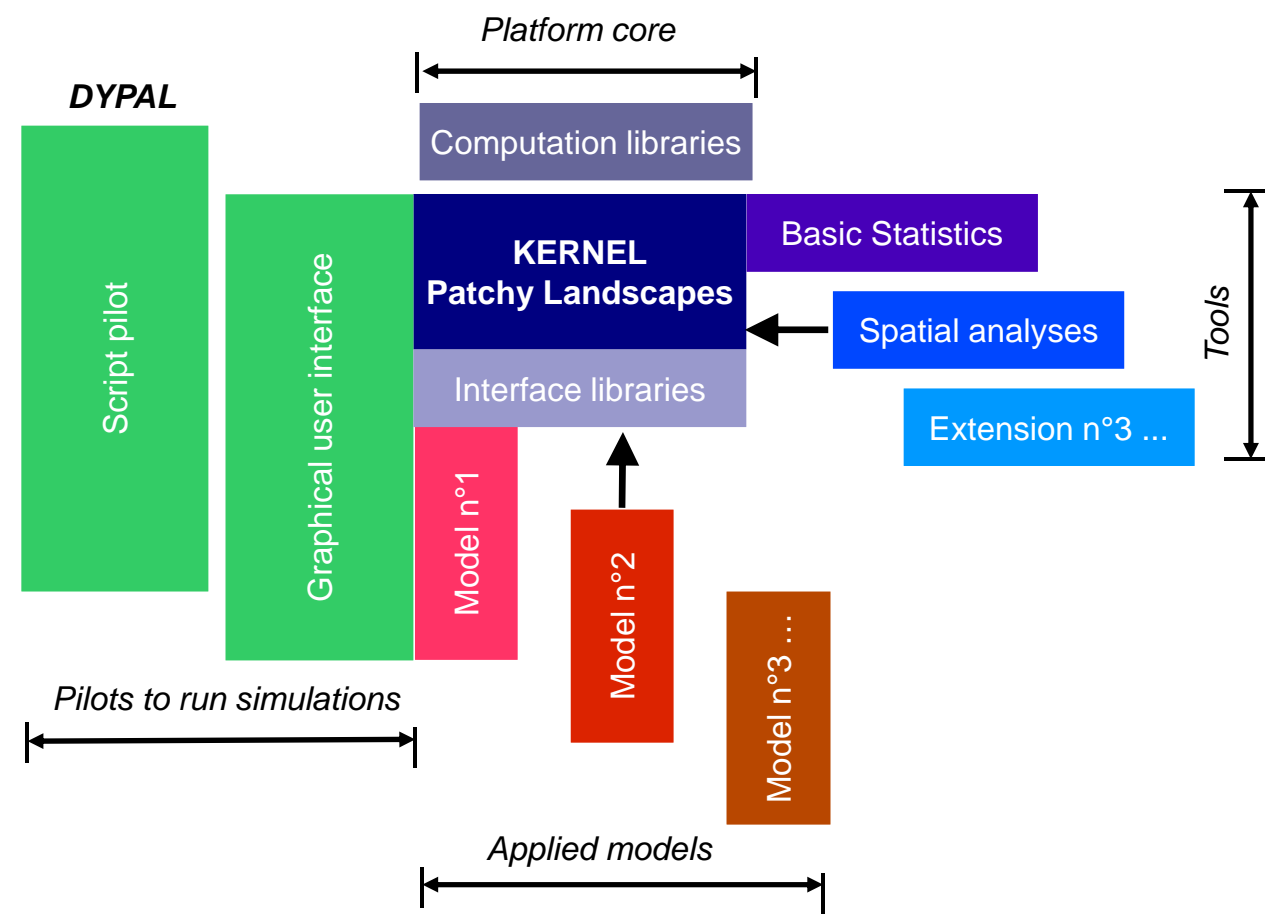

Figure 2: Scheme illustrating the principle of a modelling platform (a) and the architecture of an example: the DYPAL landscape modelling platform (b). The principle of a platform aims at finding a compromise (the greatest common divisor GCD) between a range of models dedicated to various objectives and a universal model addressing all possible objectives (as the least common multiple LCM). A platform is built on the basis of a generic kernel (bottom, in blue) dedicated to the common object modelled (here patchy landscapes of the DYPAL platform), and then developed at low cost in various dedicated models (in warm colours). 


\section{A.2 Landscape self-organization}

The concept of self-organization, inspired from the complexity theory and from physical systems, offers an appealing way for landscape modelling. By definition, a landscape would be called selforganized if at least one of its properties (e.g., the spatial distribution of tree densities) exhibits regular (i.e., with non random patterns at a specific scale) or self-similar (i.e., fractal, with a power-law scaling) behaviours (Rietkerk and Van de Koppel, 2008; Solé and Bascompte, 2006). The scientific community questions whether landscapes are often self-organized. If not, why? If yes, which ecological processes are responsible for the landscape self-organization?

The concept of self-organization has often been advocated to investigate ecological processes. For example, it has been observed that forested landscapes, both in temperate and tropical areas, sometimes exhibit self-organized patterns (Gaucherel, 2011; Scanlon et al., 2007; Solé et al., 1999). However, because it is still a phenomenological approach, self-organization is of little help to understand the forest functioning, and only provides a starting reference framework. By focusing on heterogeneous landscape dynamics, we wish to understand by which mechanisms (vegetation dispersion, competition, land-cover allocation...) self-organized structures emerge (Rietkerk and Van de Koppel, 2008; Solé and Bascompte, 2006). It is equally important to understand when self-organization fails to explain observed landscapes. What are the respective roles and weights of local rules (bottom-up controls), of more global rules (top-down controls), and of scaling properties in driving the fate of landscapes? What are the respective roles of human decisions and natural forcings? Under which conditions are simplified (yet realistic) landscape systems self-organized?

Two of the most common theoretical forest models exhibit self-organization and present interesting opportunities to understand complex landscapes: optimized and Turing-like patterns. On the one hand, recent studies have presented newly scaling properties for forested landscapes. Highlighting a link with optimal control theory and physical statistics, it is advocated that extended patchy forests may sometimes self-organize by optimizing the ecological processes involved in their generation. Preliminary forest models, based on a Hamiltonian or other summarizing functions of the forest element interactions have been developed in order to test the landscape self-organization hypothesis (Gaucherel, 2011; Lefever and Lejeune, 1997). On the other hand, Turing-like patterns concern periodical vegetation covers generated on the basis of opposite forces acting at different scales (Couteron and Lejeune, 2001; Lejeune et al., 2002). A reaction-diffusion process or, analogously, a competition-facilitation process has already proven its ability to reproduce the properties of a large range of spotted, gapped or banded vegetation covers (Lefever and Lejeune, 1997; Lejeune et al., 2002). Such vegetations appear to be self-organized too, yet on the basis of other patterns than the auto-similar properties mentioned earlier. By suggesting a relatively simple concept to describe landscapes, self-organization again offers opportunities to capture patterns and/or dynamics within parsimonious and coherent formalisms. 


\section{References}

Agarwal, C., Green, G. M., Grove, J. M., Evans, T. P. and Schweik, C. M. (2002), "A Review and Assessment of Land-Use Change Models: Dynamics of Space, Time and Human Choice", Gen. Tech. Rep., NE-297, Newtown Square, PA (USDA Forest Service). Online version (accessed 25 February 2014): http://www.treesearch.fs.fed.us/pubs/5027. (Cited on pages 6 and 7.)

Baker, W. L. (1989), "A review of models of landscape change", Landscape Ecology, 2: 111-135, [DOI]. (Cited on page 5.)

Baker, W. L. and Mladenoff, D. J. (1999), "Progress and future directions in spatial modeling of forest landscapes", in Mladenoff, D. J. and L., Baker W., eds., Spatial Modeling of Forest Landscape Change: Approaches and Applications, pp. 333-349, Cambridge; New York (Cambridge University Press). [Google Books]. (Cited on page 9.)

Barton, C. M., Ullah, I. I. and Bergin, S. (2010), "Land use, water and Mediterranean landscapes: modelling long-term dynamics of complex socio-ecological systems", Philosophical Transactions of the Royal Society of London, Series A, 368(1931): 5275-5297, [DOI]. (Cited on pages 7 and 10.)

Batty, M., Longley, P. and Fotheringham, S. (1989), "Urban growth and form: scaling, fractal, geometry, and diffusion-limited aggregation", Environment and Planning A, 21: 1447-1472, [DOI]. (Cited on page 11.)

Baudry, J., Burel, F., Aviron, S., Martin, M., Ouin, A., Pain, G. and Thenail, C. (2003), "Temporal variability of connectivity in agricultural landscapes: do farming activities help?", Landscape Ecology, 18: 303-314, [DOI]. (Cited on pages 9 and 14.)

Benoît, M., Rizzo, D., Marraccini, E., Moonen, A. C., Galli, M., Lardon, S., Rapey, H., Thenail, C. and Bonari, E. (2012), "Landscape agronomy: a new field for addressing agricultural landscape dynamics", Landscape Ecology, 27(10): 1385-1394, [DOI]. (Cited on page 14.)

Benton, T. G., Bryant, D. M., Cole, L. and Crick, H. Q. P. (2002), "Linking agricultural practice to insect and bird populations: a historical study over three decades", Journal of Applied Ecology, 39: 673-687, [DOI]. (Cited on page 5.)

Berechman, J. and Small, K. A. (1988), "Research policy and Review 25. Modeling land use and transportation: an interpretive review for growth areas", Environment and Planning A, 20(10): 1285-1309, [DOI]. (Cited on pages 10 and 14.)

Berling-Wolff, S. and Wu, J. (2004), "Modeling urban landscape dynamics: A review", Ecological Research, 19(1): 119-129, [DOI]. (Cited on pages 5, 10, 11, and 14.)

Bolliger, J., Lischke, H. and Green, D. G. (2005), "Simulating the spatial and temporal dynamics of landscapes using generic and complex models", Ecological Complexity, 2(2): 107-116, [DOI]. (Cited on pages 6,16 , and 17 .)

Brown, D. G., Page, S., Riolo, R., Zellner, M. and Rand, W. (2005), "Path dependence and the validation of agent-based models of land use", International Journal of Geographical Information Science, 19(2): 153-174, [DOI]. (Cited on page 17.)

Brown, D. G., Robinson, D. T., An, L., Nassauer, J. I., Zellner, M., Rand, W., Riolo, R., Page, S. E., Low, B. and Wang, Z. (2013), "Exurbia from the bottom-up: Confronting empirical challenges to characterizing a complex system", Geoforum, 39(2): 805-818, [DOI]. (Cited on page 7.)

Brown, I. and Castellazzi, M. (2014), "Scenario analysis for regional decision-making on sustainable multifunctional land uses", Regional Environmental Change, [DOI]. (Cited on page 7.)

Bürgi, M., Hersperger, A. M. and Schneeberger, N. (2004), "Driving forces of landscape change - current and new directions", Landscape Ecology, 19: 857-868, [DOI]. (Cited on page 17.) 
Caillault, S., Mialhe, F., Vannier, C., Delmotte, S., Kêdowidé, C., Amblard, F., Etienne, M., Bécu, N., Gautreau, P. and Houet, T. (2013), "Influence of incentive networks on landscape changes: A simple agent-based simulation approach", Environmental Modelling \&S Software, 45: 64-73, [DOI]. (Cited on pages 12 and 16.)

Castella, J. C., Kam, S. P., Quang, D. D., Verburg, P. H. and Hoanh, C. T. (2007), "Combining top-down and, bottom-up modelling approaches of land use/cover change to support public policies: Application to sustainable management of natural resources in northern Vietnam", Land Use Policy, 24(3): 531-545, [DOI]. (Cited on pages 7 and 18.)

Castellazzi, M. S., Wood, G. A., Burgess, P. J., Morris, J., Conrad, K. F. and Perry, J. N. (2008), "A systematic representation of crop rotations", Agricultural Systems, 97(1-2): 26-33, [DOI]. (Cited on page 13.)

Castellazzi, M. S., Matthews, J., Angevin, F., Sausse, C., Wood, G. A., Burgess, P.J., Brown, I., Conrad, J. F. and Perry, J. N. (2010), "Simulation scenarios of spatio-temporal arrangement of crops at the landscape scale", Environmental Modelling \& Software, 25: 1881-1889, [DOI]. (Cited on page 7.)

Christaller, W. (1972), "How I discovered the Theory of Central Places: A Report about the Origin of Central Places", in W., English P. and C., Mayfield R., eds., Man Space and Environment: Concepts in Contemporary Human Geography, pp. 601-610, Oxford (Oxford University Press). (Cited on page 11.)

Cincotta, R. P., Wisnewski, J. and Engelman, R. (2000), "Human population in the biodiversity hotspots", Nature, 404(6781): 990-992, [DOI]. (Cited on page 5.)

Clark, J. S., Lewis, M. and Horvath, L. (2001), "Invasion by extremes: Population spread with variation in dispersal and reproduction", American Naturalist, 157(5): 537-554, [DOI]. (Cited on page 9.)

Clifford, N. J. (2007), "Models in geography revisited", Geoforum, 39(2): 675-686, [DOI]. (Cited on page 5.)

Collins, S. L., Carpenter, S. R., Swinton, S. M., Orenstein, D. E., Childers, D. L., Gragson, T. L., Grimm, N. B., Morgan Grove, J., Harlan, S. L., Kaye, J. P., Knapp, A. K., Kofinas, G. P., Magnuson, J. J., McDowell, W. H., Melack, J. M., Ogden, L. A., Robertson, G. P., Smith, M. D. and Whitmeret, A. C. (2011), "An integrated conceptual framework for long-term social-ecological research", Frontiers in Ecology and the Environment, 9, [DOI]. (Cited on page 5.)

Costanza, R. and Voinov, A., eds. (2004), Landscape Simulation Modeling: A Spatially Explicit, Dynamic Approach, Modeling Dynamic Systems, New York (Springer). [Google Books]. (Cited on pages 5, 7, and 12.)

Cousens, R., Dytham, C. and Law, R. (2008), Dispersal in Plants: A Population Perspective, Oxford; New York (Oxford University Press). (Cited on page 9.)

Cousins, S. A. O., Lavorel, S. and Davies, I. (2003), "Modelling the effects of landscape pattern and grazing regimes on the persistence of plant species with high conservation value in grasslands in south-eastern Sweden", Landscape Ecology, 18(3): 315-332, [DOI]. (Cited on page 9.)

Couteron, P. and Lejeune, O. (2001), "Periodic spotted patterns in semi-arid vegetation explained by a propagation-inhibition model", Journal of Ecology, 89(4): 616-628, [DOI]. (Cited on pages 10, 18, and 22.)

Crawford, T. W., Messina, J. P., Manson, S. M. and O'Sullivan, D. (2005), "Complexity science, complex systems, and land-use research", Environment and Planning B: Planning and Design, 32: 792-798, [DOI]. (Cited on page 6.)

Dalgaard, T., Jørgensen, U., Olesen, J. E., Jensen, E. S. and Kristensen, E. S. (2006), "Looking at Biofuels and Bioenergy", Science, 312(5781): 1743-1743, [DOI]. (Cited on page 5.) 
de Coligny, F. (2006), "Efficient Building of Forestry Modelling Software with the Capsis Methodology", in Fourcaud, T. and Zhang, X.-P., eds., Plant Growth Modelling and Applications - PMA06, Proceedings of the Second International Symposium, Beijing, November 13-17, 2006, pp. 216-222, Los Alamitos, CA (IEEE Computer Society), [DOI]. (Cited on pages 9, 12, and 18.)

Degenne, P., Lo Seen, D., Parigot, D., Forax, R., Tran, A., Ait Lahcen, A., Curé, O. and Jeansoulin, R. (2009), "Design of a Domain Specific Language for modelling processes in landscapes", Ecological Modelling, 220(24): 3527-3535, [DOI]. (Cited on pages 11, 12, 13, 16, and 18.)

D'Souza, R. M., Borgs, C., Chayes, J. T., Berger, N. and Kleinberg, R. D. (2007), "Emergence of tempered preferential attachment from optimization", Proceedings of the National Academy of Sciences of the United States of America, 104(15): 6112-6117, [DOI]. (Cited on page 17.)

Dufour-Kowalski, S., Courbaud, B., Dreyfus, P., Meredieu, C. and de Coligny, F. (2011), "Capsis: an open software framework and community for forestry modelling", Annals of Forest Science, 69: 221-233, [DOI]. (Cited on pages 9 and 12.)

Dungan, J. L., Perry, J. N., Dale, M. R. T., Legendre, P., Citron-Pousty, S., Fortin, M.-J., Jakomulska, A., Miriti, M. and Rosenberg, M. S. (2002), "A balanced view of scale in spatial statistical analysis", Ecography, 25(5): 626-640, [DOI]. (Cited on page 16.)

Fall, A. and Fall, J. (2001), "A domain-specific language for models of landscape dynamics", Ecological Modelling, 141(1-3): 1-18, [DOI]. (Cited on pages 12 and 18.)

Finney, M. A. (1999), "Mechanistic modeling of landscape fire patterns", in Mladenoff, D. J. and Baker, W. L., eds., Spatial Modeling of Forest Landscape Change: Approaches and Applications, pp. 186-210, Cambridge; New York (Cambridge University Press). [Google Books]. (Cited on page 9.)

Flanders, D., Hall-Beyer, M. and Pereverzoff, J. (2003), "Preliminary evaluation of eCognition objectbased software for cut block delineation and feature extraction", Canadian Journal of Remote Sensing, 29(4): 441-452, [DOI]. (Cited on page 13.)

Foot, D. H. S. (1981), Operational Urban Models: An Introduction, London; New York (Methuen). (Cited on page 10.)

Forman, R. T. T. and Godron, M. (1986), Landscape Ecology, New York (John Wiley \& Sons). (Cited on pages $5,6,12,14,15$, and 16.$)$

Gallagher, R. and Appenzeller, T. (1999), "Beyond reductionism", Science, 284(5411): 79-79, [DOI]. (Cited on page 16.)

Gardner, R. H. (1999), "RULE: map generation and a spatial analysis program", in Klopatek, J. M. and Gardner, R. H., eds., Landscape Ecological Analysis: Issue and application, pp. 280-303, New York (Springer). (Cited on pages 12 and 20.)

Gardner, R. H. and Urban, D. L. (2007), "Neutral models for testing landscape hypotheses", Landscape Ecology, 22(1): 15-29, [DOI]. (Cited on pages 12 and 15.)

Gardner, R. H., Milne, B. T., Turner, M. G. and O'Neill, R. V. (1987), "Neutral models for the analysis of broad-scale pattern", Landscape Ecology, 1: 19-28, [DOI]. (Cited on pages 5 and 20.)

Gaucherel, C. (2008), "Neutral models for polygonal landscapes with linear networks", Ecological Modelling, 219(1-2): 39-48, [DOI]. (Cited on pages 14, 16, 17, and 20.)

Gaucherel, C. (2011), "Self-organization of patchy landscapes: Hidden optimization of ecological processes", Journal of Ecosystem \& Ecography, 1(2), [DOI]. (Cited on pages 17, 18, and 22.)

Gaucherel, C. and Houet, T. (2009), "Preface to the selected papers on spatially explicit landscape modelling: Current practices and challenges", Ecological Modelling, 220: 3477-3480, [DOI]. (Cited on page 6.) 
Gaucherel, C., Fleury, D., Auclair, A. and Dreyfus, P. (2006a), "Neutral models for patchy landscapes", Ecological Modelling, 197(1-2): 159-170, [DOI]. (Cited on pages 12, 15, and 20.)

Gaucherel, C., Giboire, N., Viaud, V., Houet, T., Baudry, J. and Burel, F. (2006b), "A domain specific language for patchy landscape modelling: the brittany agricultural mosaic as a case study", Ecological Modelling, 194(1-3): 233-243, [DOI]. (Cited on pages 7 and 12.)

Gaucherel, C., Alleaume, S. and Hely, C. (2008), "The comparison map profile method: A strategy for multiscale comparison of quantitative and qualitative images", Transactions on Geoscience and Remote Sensing, 46(9): 2708-2719, [DOI]. (Cited on page 15.)

Gaucherel, C., Griffon, S., Misson, L. and Houet, T. (2010), "Combining process-based models for future biomass assessment at landscape scale", Landscape Ecology, 25: 300, [DOI]. (Cited on pages 7, 11, and 18.)

Gaucherel, C., Boudon, F., Houet, T., Castets, M. and Godin, C. (2012), "Understanding Patchy Landscape Dynamics: Towards a Landscape Language", PLoS ONE, 7(9): e46064, [DOI]. (Cited on pages 16, 17, and 18.)

Grossman, A. and Morlet, J. (1984), "Decomposition of Hardy functions into square integrable wavelets of constant shape", SIAM Journal on Mathematical Analysis, 15(4): 723-736, [DOI]. (Cited on page 15.)

Gusdorf, F. and Hallegatte, S. (2007), "Compact or spread-out cities: Urban planning, taxation, and the vulnerability to transportation shocks", Energy Policy, 35(10): 4826-4838, [DOI]. (Cited on page 10.)

Gusdorf, F., Hallegatte, S. and Lahellec, A. (2008), "Time and space matter: How urban transitions create inequality", Global Environmental Change, 18(4): 708-719, [DOI]. (Cited on page 10.)

Gustafson, E. J. (1998), "Quantifying landscape spatial pattern: What is the state of the art?", Ecosystems, 1(2): 143-156, [DOI]. (Cited on page 12.)

Gustafson, E. J. (2013), "When relationships estimated in the past cannot be used to predict the future: using mechanistic models to predict landscape ecological dynamics in a changing world", Landscape Ecology, 28(8): 1429-1437, [DOI]. (Cited on pages 12, 14, and 18.)

Haase, D. and Schwarz, N. (2009), "Simulation Models on Human-Nature Interactions in Urban Landscapes: A Review Including Spatial Economics, System Dynamics, Cellular Automata and Agent-based Approaches", Living Reviews in Landscape Research, 3: lrlr-2009-2, [DOI]. URL (accessed 25 February 2014): http://www.livingreviews.org/lrlr-2009-2. (Cited on pages 6 and 7.)

He, C. Y., Zhao, Y. Y., Tian, J. and Shi, P. J. (2013), "Modeling the urban landscape dynamics in a megalopolitan cluster area by incorporating a gravitational field model with cellular automata", Landscape and Urban Planning, 113: 78-89, [DOI]. (Cited on pages 11 and 17.)

Henne, P. D., Elkin, C. M., Reineking, B., Bugmann, H. and Tinner, W. (2011), "Did soil development limit spruce (Picea abies) expansion in the Central Alps during the Holocene? Testing a palaeobotanical hypothesis with a dynamic landscape model", Journal of Biogeography, 38(5): 933-949, [DOI]. (Cited on page 13.)

Houet, T., Loveland, T. R., Hubert-Moy, L., Gaucherel, C., Napton, D., Barnes, C. A. and Sayler, K. (2010), "Exploring subtle land use and land cover changes: a framework based on future landscape studies", Landscape Ecology, 25: 249-266, [DOI]. (Cited on pages 7, 14, and 18.)

IPCC (2007), "Climate Change 2007", Cambridge; New York (Cambridge University Press). (Cited on page 5.)

Jørgensen, S. E. and Bendoricchio, G. (2001), Fundamentals of ecological modelling, Kidlington (Elsevier), 3rd edn. [Google Books]. (Cited on page 11.) 
Keane, R. E., Cary, G. J., Flannigan, M. D., Parsons, R. A., Davies, I. D., King, K. J., Li, C., Bradstock, R. A. and Gill, M. (2013), "Exploring the role of fire, succession, climate, and weather on landscape dynamics using comparative modeling", Ecological Modelling, 266: 172-186, [DOI]. (Cited on page 9.)

Kolb, M., Mas, J.-F. and Galicia, L. (2013), "Evaluating drivers of land-use change and transition potential models in a complex landscape in Southern Mexico", International Journal of Geographical Information Science, 27(9): 1804-1827, [DOI]. (Cited on page 17.)

Kotliar, N. B. and Wiens, J. A. (1990), "Multiple scales of patchiness and patch structure: a hierarchical framework for the study of heterogeneity", Oikos, 59: 523-60, [DOI]. (Cited on pages 5, 9, 12, and 20.)

Krol, M. S. and Bronstert, A. (2007), "Regional integrated modelling of climate change impacts on natural resources and resource usage in semi-arid Northeast Brazil", Environmental Modelling \& Software, 22(2): 259-268, [DOI]. (Cited on page 10.)

Kurz, W. A., Beukema, S. J., Klenner, W., Greenough, J. A., Robinson, D. C. E., Sharpe, A. D. and Webb, T. M. (2000), "TELSA: the Tool for Exploratory Landscape Scenario Analyses", Computers and Electronics in Agriculture, 27(1-3): 227-242, [DOI]. (Cited on page 9.)

Lambin, E. F. (1997), "Modelling and monitoring land-cover change processes in tropical regions", Progress in Physical Geography, 21(3): 375-393, [DOI]. (Cited on pages 5, 6, 7, 10, and 16.)

Lambin, E. F., Rounsevell, M. D. A. and Geist, H. J. (2000), "Are agricultural land-use models able to predict changes in land-use intensity?", Agriculture, Ecosystems \& Environment, 82(1-3): 321-331, [DOI]. (Cited on page 7.)

Lambin, E. F., Turner, B. L., Geist, H. J., Agbola, S. B., Angelsen, A., Bruce, J. W., Coomes, O. T., Dirzo, R., Fischer, G., Folke, C., George, P. S., Homewood, K., Imbernon, J., Leemans, R., Li, X., Moran, E. F., Mortimore, M., Ramakrishnan, P. S., Richards, J. F., Skånes, H., Steffen, W., Stone, G. D., Svedin, U.and Veldkamp, T. A, Vogel, C. and Xu, J. (2001), "The causes of land-use and land-cover change: moving beyond the myths", Global Environmental Change, 11(4): 261-269, [DOI]. (Cited on page 7.)

Le Ber, F., Benoît, M., Schott, C., Mari, J.-F. and Mignolet, C. (2006), "Studying crop sequences with CarrotAge, a HMM-based data mining software", Ecological Modelling, 191(1): 170-185, [DOI]. (Cited on pages 9,14 , and 18.)

Lefever, R. and Lejeune, O. (1997), "On the origin of tiger bush", Bulletin of Mathematical Biology, 59: 263-294, [DOI]. (Cited on page 22.)

Lejeune, O., Tlidi, M. and Couteron, P. (2002), "Localized vegetation patches: A self-organized response to resource scarcity", Physical Review E, 66(1), [DOI]. (Cited on pages 10 and 22.)

Levin, S. A., Powell, T. M. and Steele, J. H., eds. (1993), Patch Dynamics, Lecture Notes in Biomathematics, 96, Berlin; New York (Springer), [DOI]. (Cited on pages 15, 18, and 20.)

Levins, R. (1966), "The strategy of model building in population biology", American Scientist, 54: 421431. (Cited on page 11.)

Li, H. and Reynolds, J. F. (1994), "A simulation experiment to quantify spatial heterogeneity in categorical maps", Ecology, 75: 2446-2455, [DOI]. (Cited on pages 9, 12, and 13.)

Lindenmayer, A. (1968a), "Mathematical models for cellular interaction in developments I. Filaments with one-sided inputs", Journal of Theoretical Biology, 18: 280-299, [DOI]. (Cited on page 18.)

Lindenmayer, A. (1968b), "Mathematical models for cellular interaction in developments II. Simple and branching filaments with two-sided inputs", Journal of Theoretical Biology, 18: 300-315, [DOI]. (Cited on page 18.) 
Looijen, R. C. (1998), Holism and Reductionism in Biology and Ecology: The mutual dependence of higher and lower level research programmes, Ph.D. thesis, University of Groningen, Groningen. Online version (accessed 25 February 2014):

http://irs.ub.rug.nl/ppn/168456559. (Cited on page 16.)

Lowry, I. S. (1964), "A model of Metropolis", RM-4035-RC, Santa Monica, CA (The Rand Corporation). (Cited on page 10.)

Mackey, B. G. (2000), "GIS for ecology: an introduction", International Journal of Geographical Information Science, 14(1): 107-107. (Cited on pages 13 and 17.)

Mas, J.-F., Kolb, M., Paegelow, M., Camacho Olmedo, M. T. and Houet, T. (2014), "Inductive patternbased land use/cover change models: A comparison of four software packages", Environmental Modelling ES Software, 51: 94-111, [DOI]. (Cited on pages 7 and 11.)

Matthews, R. B., Gilbert, N. G., Roach, A., Polhill, J. G. and Gotts, N. M. (2007), "Agent-based land-use models: a review of applications", Landscape Ecology, 22(10): 1447-1459, [DOI]. (Cited on page 7.)

MEA (2005), Ecosystems and Human Well-being: Current State and Trends, Millennium Ecosystem Assessment Series, 1, Washington, DC (Island Press). [Google Books]. Online version (accessed 25 February 2014):

http://www.millenniumassessment.org/en/Condition.html. (Cited on page 5.)

Mladenoff, D. J. (2004), "LANDIS and forest landscape models", Ecological Modelling, 180(1): 7-19, [DOI]. (Cited on page 9.)

Moustakas, A., Sakkos, K., Wiegand, K., Ward, D., Meyer, K. M. and Eisinger, D. (2009), "Are savannas patch-dynamic systems? A landscape model", Ecological Modelling, 220(24): 3576-3588, [DOI]. (Cited on pages 13 and 15.)

Müller, F. and Steinhardt, U. (2003), "Landscape modelling and landscape analysis", Ecological Modelling, 168(3): 215-216, [DOI]. (Cited on page 11.)

Nathan, R., Schurr, F. M., Spiegel, O., Steinitz, O., Trakhtenbrot, A. and Tsoar, A. (2008), "Mechanisms of long-distance seed dispersal", Trends in Ecology 83 Evolution, 23(11): 638-647, [DOI]. (Cited on page 9.)

O'Neill, R. V., DeAngelis, D. L., Waide, J. B. and Allen, T. H. F. (1986), A Hierarchical Concept of Ecosystems, Monographs in Population Biology, 23, Princeton, NJ (Princeton University Press). [Google Books]. (Cited on page 15.)

Paegelow, M., Camacho Olmedo, M. T., Mas, J.-M., Houet, T. and Pontius Jr, R. G. (2013), "Land change modeling: moving beyond projections", International Journal of Geographical Information Science, 27(9): 1691-1695, [DOI]. (Cited on page 11.)

Pascual, M. and Guichard, F. (2005), "Criticality and disturbance in spatial ecological systems", Trends in Ecology 85 Evolution, 20(2): 88-95, [DOI]. (Cited on pages 5, 13, 14, 15, and 17.)

Paudel, S. and Yuan, F. (2012), "Assessing landscape changes and dynamics using patch analysis and GIS modeling", International Journal of Applied Earth Observation and Geoinformation, 16: 66-76, [DOI]. (Cited on pages 5, 15, and 17.)

Perry, G. L. W. and Enright, N. J. (2006), "Spatial modelling of vegetation change in dynamic landscapes: a review of methods and applications", Progress in Physical Geography, 30(1): 47-72, [DOI]. (Cited on page 9.)

Pontius Jr, R. G., Boersma, W., Castella, J. F., Clarke, K., Nijs, T., Dietzel, C., Duan, Z., Fotsing, E., Goldstein, N., Kok, K., Koomen, E., Lippitt, C. D., McConnell, W., Mohd Sood, A., Pijanowski, B., Pithadia, S., Sweeney, S., Trung, T. N., Veldkamp, A. T. and Verburg, P. H. (2008), "Comparing input, output, and validation maps for several models of land change", Annals of Regional Science, 42(1): 11-47, [DOI]. (Cited on page 7.) 
Proulx, S. R., Promislow, D. E. L. and Phillips, P. C. (2005), "Network thinking in ecology and evolution", Trends in Ecology 8 Evolution, 20(6): 345-353, [DOI]. (Cited on pages 5, 11, 14, 16, and 17.)

Pumain, D. (1989), "Spatial dynamics and urban models", in Hauer, J., Timmermans, H. and Wrigley, N., eds., Urban Dynamics and Spatial Choice Behaviour, Theory and Decision Library, 49, pp. 155-174, Dordrecht (Kluwer). [Google Books]. (Cited on page 11.)

Pumain, D., ed. (2006), Hierarchy in Natural and Social Sciences, Methodos Series, 3, Dordrecht (Springer). (Cited on pages 5, 11, 13, and 14.)

Retho, B., Gaucherel, C. and Inchausti, P. (2008), "Spatially explicit population dynamics of Pterostichus melanarius I11. (Coleoptera: Carabidae) in response to changes in the composition and configuration of agricultural landscapes", Landscape and Urban Planning, 84: 191-199, [DOI]. (Cited on page 14.)

Rietkerk, M. and Van de Koppel, J. (2008), "Regular pattern formation in real ecosystems", Trends in Ecology E Evolution, 23(3): 169-175, [DOI]. (Cited on pages 10, 14, and 22.)

Rizzo, D., Marraccini, E., Lardon, S., Rapey, H., Debolini, M., Benoît, M. and Thenail, C. (2013), "Farming systems designing landscapes: land management units at the interface between agronomy and geography", Geografisk Tidsskrift - Danish Journal of Geography, 113(2): 71-86, [DOI]. (Cited on page 14.)

Rounsevell, M. D. A., Pedroli, B., Erb, K.-H., Gramberger, M., Gravsholt Busck, A., Haberl, H., Kristensen, S., Kuemmerle, T., Lavorel, S., Lindner, M., Lotze-Campen, H., Metzger, M. J., Murray-Rust, D., Popp, A., Pérez-Soba, M., Reenberg, A., Vadineanu, A., Verburg, P. H. and Wolfslehneret, B. (2012), "Challenges for land system science", Land Use Policy, 29(4): 899-910, [DOI]. (Cited on page 5.)

Saltré, F., Saint-Amant, R., Gritti, E. S., Brewer, S., Gaucherel, C., Davis, B. A. S. and Chuine, I. (2013), "Climate or migration: what limited European beech post-glacial colonization?", Global Ecology and Biogeography, 22, [DOI]. (Cited on pages 9 and 17.)

Sankaran, M., Hanan, N. P., Scholes, R. J., Ratnam, J., Augustine, D. J., Cade, B. S., Gignoux, J., Higgins, S. I., Le Roux, X., Ludwig, F., Ardo, J., Banyikwa, F., Bronn, A., Bucini, G., Caylor, K. K., Coughenour, M. B., Diouf, A., Ekaya, W., Feral, C. J., February, E. C., Frost, P. G. H., Hiernaux, P., Hrabar, H., Metzger, K. L., Prins, H. H. T., Ringrose, S., Sea, W., Tews, J., Worden, J. and Zambatis, N. (2005), "Determinants of woody cover in African savannas", Nature, 438(7069): 846-849, [DOI]. (Cited on page 10.)

Saura, S. and Martínez-Millán, J. (2000), "Landscape patterns simulation with a modified random clusters method", Landscape Ecology, 15(7): 661-678, [DOI]. (Cited on pages 8, 12, and 20.)

Scanlon, T. M., Caylor, K. K., Levin, S. A. and Rodriguez-Iturbe, I. (2007), "Positive feedbacks promote power-law clustering of Kalahari vegetation", Nature, 449(7159): 209-212, [DOI]. (Cited on pages 10, 14,15 , and 22.)

Scheffer, M. and Carpenter, S. R. (2003), "Catastrophic regime shifts in ecosystems: linking theory to observation", Trends in Ecology 8 Evolution, 18(12): 648-656, [DOI]. (Cited on page 10.)

Scheller, R. M. and Mladenoff, D. J. (2007), "An ecological classification of forest landscape simulation models: tools and strategies for understanding broad-scale forested ecosystems", Landscape Ecology, 22(4): 491-505, [DOI]. (Cited on pages 5, 9, and 11.)

Schröder, B. and Seppelt, R. (2006), "Analysis of pattern-process interactions based on landscape models: Overview, general concepts, and methodological issues", Ecological Modelling, 199(4): 505-516, [DOI]. (Cited on pages 5 and 16.)

Seidl, R., Rammer, W., Scheller, R. M. and Spies, T. A. (2012), "An individual-based process model to simulate landscape-scale forest ecosystem dynamics", Ecological Modelling, 231: 87-100, [DOI]. (Cited on pages 9 and 12.) 
Shochat, E., Warren, P. S., Faeth, S. H., McIntyre, N. E. and Hope, D. (2006), "From patterns to emerging processes in mechanistic urban ecology", Trends in Ecology 83 Evolution, 21(4): 186-191, [DOI]. (Cited on page 5.$)$

Shugart, H. H. (1984), A Theory of Forest Dynamics: The Ecological Implications of Forest Succession Models, New York (Springer). (Cited on page 9.)

Solé, R. V. and Bascompte, J. (2006), Self-Organization in Complex Ecosystems, Monographs in Population Biology, MPB-42, Princeton, NJ (Princeton University Press). (Cited on pages 6, 14, 15, 17, and 22.)

Solé, R. V., Manrubia, S. C., Benton, M., Kauffman, S. and Bak, P. (1999), "Criticality and scaling in evolutionary ecology", Trends in Ecology \& Evolution, 14(4): 156-160, [DOI]. (Cited on page 22.)

Strogatz, S. H. (2001), "Exploring complex networks", Nature, 410: 268-276, [DOI]. (Cited on pages 14 and 16.)

Tepley, A. J. and Thomann, E. A. (2012), "Analytical approximation of a stochastic, spatial simulation model of fire and forest landscape dynamics", Ecological Modelling, 233: 41-51, [DOI]. (Cited on page 18.)

Thenail, C. and Baudry, J. (2004), "Variation of the farm spatial land use pattern according to the structure of the hedgerow network (bocage) landscape: a study case in northeast Brittany, France", Agriculture, Ecosystems \& Environment, 101: 53-72, [DOI]. (Cited on pages 14 and 16.)

Thenail, C., Joannon, A., Capitaine, M., Souchère, V., Mignolet, C., Schermann, N., Di Pietro, F., Pons, Y., Gaucherel, C., Viaud, V. and Baudry, J. (2009), "The contribution of crop-rotation organization in farms to crop-mosaic patterning at local landscape scales", Agriculture, Ecosystems E Environment, 131(3-4): 207-219, [DOI]. (Cited on pages 7 and 14.)

Thomas, I., Frankhauser, P. and Biemacki, C. (2008), "The morphology of built-up landscapes in Wallonia (Belgium): A classification using fractal indices", Landscape and Urban Planning, 84(2): 99-115, [DOI]. (Cited on pages 5 and 11.)

Tischendorf, L. (2001), "Can landscape indices predict ecological processes consistently?", Landscape Ecology, 16(3): 235-254, [DOI]. (Cited on page 12.)

Tischendorf, L. and Fahrig, L. (2000), "On the usage and measurement of landscape connectivity", Oikos, 90(9-19), [DOI]. (Cited on page 16.)

Turner, B., Lambin, E. and Reenberg, A. (2007), "The emergence of land change science for global environmental change and sustainability", Proceedings of the National Academy of Sciences of the United States of America, 104(52): 20666-20671, [DOI]. (Cited on page 6.)

Turner, M. G. and Gardner, R. H., eds. (1991), Quantitative Methods in Landscape Ecology, Ecological Studies, 82, New York (Springer). (Cited on pages 5, 14, 15, and 16.)

Usher, M. B. (1981), "Modelling ecological succession, with particular reference to Markovian models", Vegetatio, 46: 11-18, [DOI]. (Cited on pages 7, 9, and 13.)

Valbuena, D., Verburg, P. H., Bregt, A. K. and Ligtenberg, A. (2010), "A generic framework to model local decisions and regional processes: an agent based approach for regional land-use research", Landscape Ecology, 25: 185-199, [DOI]. (Cited on page 7.)

Verburg, P. H. and Veldkamp, A. (2004), "Projecting land use transitions at forest fringes in the Philippines at two spatial scales", Landscape Ecology, 19(1): 77-98, [DOI]. (Cited on pages 5, 7, 11, and 13.)

Verburg, P. H., Soepboer, W., Veldkamp, A., Limpiada, R., Espaldon, V. and Mastura, S. S. A. (2002), "Modeling the spatial dynamics of regional land use: The CLUE-S model", Environmental Management, 30(3): 391-405, [DOI]. (Cited on page 7.) 
Verburg, P. H., Schot, P. P., Dijst, M. J. and Veldkamp, A. (2004), "Land use change modelling: current practices and research priorities", GeoJournal, 61(4): 309-324, [DOI]. (Cited on pages 5 and 12.)

Verburg, P. H., Kok, K., Pontius Jr, R. G. and Veldkamp, A. (2006), "Modelling Land-Use and LandCover Change", in Lambin, E. F. and Geist, H., eds., Land-Use and Land-Cover Change: Local Processes, Global Impacts, Global Change - The IGBP Series, pp. 117-135, Berlin; New York (Springer). [Google Books]. (Cited on page 6.)

Viaud, V., Angers, D. A. and Walter, C. (2010), "Toward Landscape-Scale Modeling of Soil Organic Matter Dynamics in Agroecosystems", Soil Science Society of America Journal, 74(6): 1847-1860, [DOI]. (Cited on pages 7, 13, and 15.)

Viguié, V., Hallegatte, S. and Rozenberg, J. (2014), "Downscaling long term socio-economic scenarios at city scale: A case study on Paris", Technological Forecasting E Social Change, [DOI]. (Cited on page 11.)

Vitousek, P. M., Mooney, H. A., Lubchenco, J. and Melillo, J. M. (1997), "Human domination of Earth's ecosystems", Science, 277(5325): 494-499, [DOI]. (Cited on page 5.)

Wang, B. C. and Smith, T. B. (2002), "Closing the seed dispersal loop", Trends in Ecology EG Evolution, 17(8): 379-385, [DOI]. (Cited on page 9.)

White, R. and Engelen, G. (1993), "Cellular-automata and fractal urban form: a cellular modeling approach to the evolution of urban land-use patterns", Environment and Planning A, 25(8): 1175-1199, [DOI]. (Cited on page 11.)

Whittle, P. (1996), Optimal Control: Basics and Beyond, Chichester; New York (John Wiley \& Sons). (Cited on pages 17 and 18.)

Willemen, L., Veldkamp, A., Verburg, P. H., Hein, L. and Leemans, R. (2012), "A multi-scale modelling approach for analysing landscape service dynamics", Journal of Environmental Management, 100: 8695, [DOI]. (Cited on pages 7, 12, and 15.)

With, K. A. and King, A. W. (1997), "The use and misuse of neutral landscape models in ecology", Oikos, 79: 219-229, [DOI]. (Cited on pages 5, 12, 15, and 20.) 